\title{
MAXIMUM MISSILE RANGES FROM \\ CASED EXPLOSIVE CHARGES
}

by

R. H. BISHOP -5112

July 1958

\begin{abstract}
Curves are calculated and plotted to show maximum missile ranges from TNT charges cased with aluminum or steel of various thicknesses. The maximum initial missile velocity is assumed to be 10,000 feet per second. The basis for this assumption is explained. General trajectory formulas are derived in the Appendix from which the range may be enlculated for any initial missile velocity, as determined from the ratio of the case weight to the explo sive weight.
\end{abstract}




\section{DISCLAIMER}

This report was prepared as an account of work sponsored by an agency of the United States Government. Neither the United States Government nor any agency Thereof, nor any of their employees, makes any warranty, express or implied, or assumes any legal liability or responsibility for the accuracy, completeness, or usefulness of any information, apparatus, product, or process disclosed, or represents that its use would not infringe privately owned rights. Reference herein to any specific commercial product, process, or service by trade name, trademark, manufacturer, or otherwise does not necessarily constitute or imply its endorsement, recommendation, or favoring by the United States Government or any agency thereof. The views and opinions of authors expressed herein do not necessarily state or reflect those of the United States Government or any agency thereof. 


\section{DISCLAIMER}

Portions of this document may be illegible in electronic image products. Images are produced from the best available original document. 
TABLE OF CONTENTS

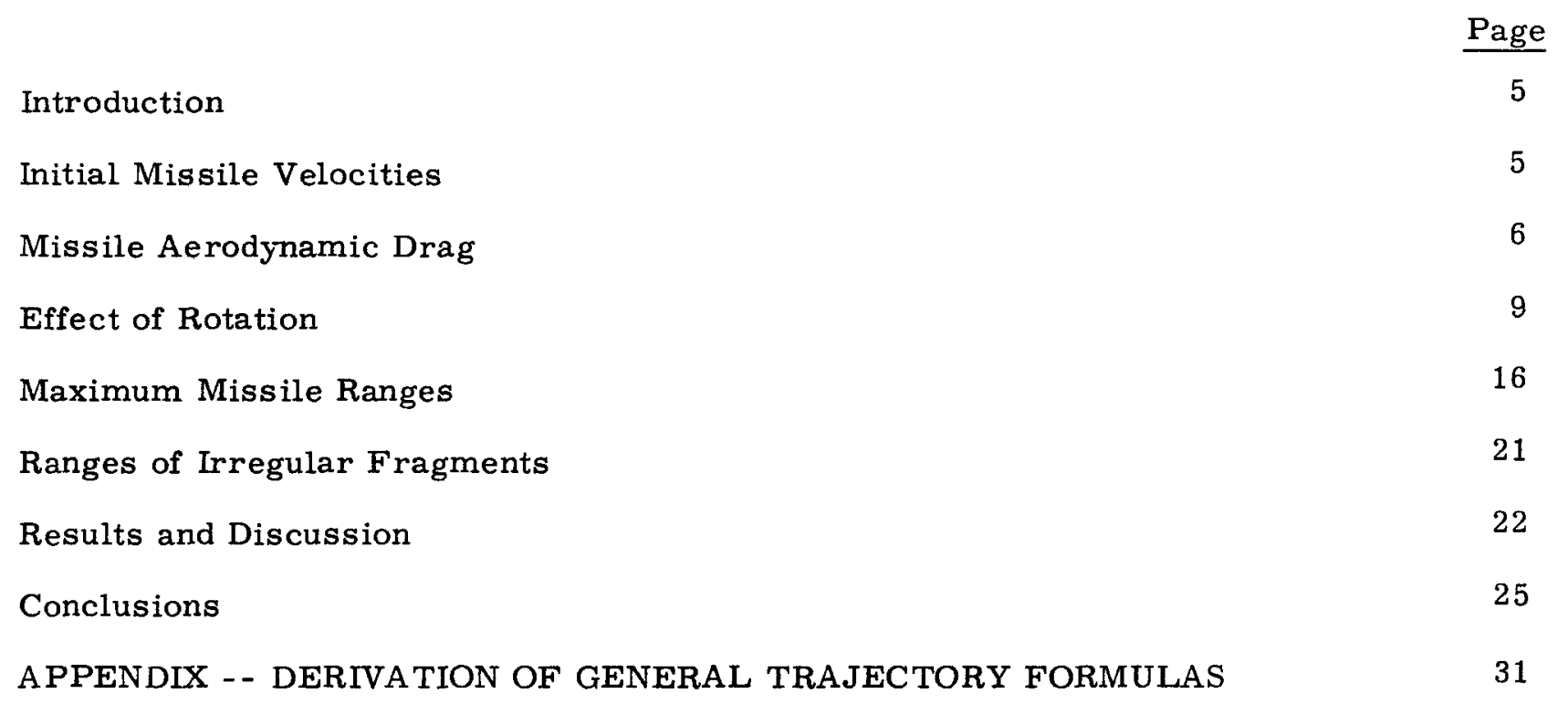

\section{LIST OF ILLUSTRATIONS}

Fig. 1 - - Solution of range equation $A-49$, wide range of $Z_{R} \quad 27$

Fig. 2 -- Solution of range equation A-49, small values of $Z_{R} \quad 28$

Fig. 3 - - Initial angle for maximum range 29

Fig. 4 -- Maximum ranges of fragments with initial speed of $10,000 \mathrm{ft} / \mathrm{sec} \quad 30$ 


\section{MAXIMUM MISSILE RANGES FROM \\ CASED EXPLOSIVE CHARGES}

\section{Introduction}

There has been general interest in the problem of determining the hazard resulting from fragmentary missiles from cased explosive charges. In particular, use of the cube root formula* is believed to be unsatisfactory except as a rough estimate, since missiles have been observed beyond the limits predicted by this formula. In this report an analysis is made which takes account of the missile size and shape, as well as the weight of the explosive charge. It is found that missile size (or thickness) is the most important single factor in determining maximum range. Missile thickness is the same as the thickness of the surrounding case, unless folding occurs.

\section{Initial Missile Velocities}

It has been shown that the initial fragment velocity $V_{0}$ can be calculated from the Gurney energy-density constant $(2 E)^{1 / 2}$ in conjunction with $R$, the ratio of case weight to explosive charge weight. ${ }^{1,4}$ For a cylinder containing uniformly packed explosive material the relation is

$$
V_{o}=(2 E)^{\frac{1}{2}}(0.5+R)^{-\frac{1}{2}}
$$

For a sphere, the expression $(0.5+R)$, in the above formula is replaced by $(0.6+R)$, which results in a slightly lower fragment velocity. ${ }^{4}$ This case is not considered here, since only maximum velocities are of interest in the estimation of maximum missile ranges.

The greatest possible fragment velocity occurs when the case weight is negligible compared to the explosive weight. Then $R$ approaches zero, and the initial fragment velocity $\mathrm{V}_{\mathrm{o}}$ approaches $\mathrm{V}_{\mathrm{m}}$, where

\footnotetext{
${ }^{*}$ Safe Distance $($ feet $)=600(\text { charge } w t)^{1 / 3}$ with explosive charge weight measured in pounds of TNT equivalent.
} 


$$
\mathrm{V}_{\mathrm{m}}=(1.41)(2 \mathrm{E})^{\frac{1}{2}} \mathrm{ft} / \mathrm{sec}=\text { Maximum initial fragment velocity }
$$

The Gurney energy-density constant $(2 \mathrm{E})^{1 / 2}$ (feet per second) is tabulated in Ref.1 for a number of different explosives. For TNT the value of $(2 \mathrm{E})^{1 / 2}$ is $6940 \mathrm{ft} / \mathrm{sec}$. Thus for TNT, after multiplying by 1.41

$$
V_{m}=9800 \mathrm{ft} / \mathrm{sec}
$$

For other chemical explosives the maximum initial fragment velocities differ only slightly from the value for TNT.

Therefore, it will be assumed that any case fragment moves initially at a speed not greater than 10,000 feet per second.

\section{Missile Aerodynamic Drag}

Once the maximum missile velocity has been assumed, the only remaining problem is to determine the aerodynamic drag force on any shrapnel particle resulting from the exploding case. Various drag coefficients are given by Hoerner for a number of regular shapes at subsonic and supersonic velocities up to a Mach number of 10 (Chapter 16). ${ }^{2}$ Since the speed of sound is about 1100 feet per second, a Mach number of 10 corresponds to the initial fragment velocity assumed as a maximum in this report.

In order to relate this information to the calculation of drag forces on irregular shapes such as the shrapnel fragments, it is necessary to consider the aerodynamic drag mechanisms operating at supersonic velocities. Only two distinct classes of shapes need be mentioned. The first class consists of regularly shaped projectiles which have sharppointed conical or wedge-shaped noses. There is a negligible chance that a shrapnel fragment would be produced which possessed a sufficiently regular shape to fall in this class. Even if one did exist, it would not in general have its center of mass located so as to insure a stable motion through the air with the sharp point or edge headed forward at all times.

For these reasons it is only necessary to consider the second class of shapes, ie, all those which do not have the special characteristics of the first class. A projectile of the second class is characterized by a relatively constant drag coefficient over a wide range of supersonic velocities. 
Except for regularly shaped round bodies (eg, spheres or cylinders), the drag coefficient $C_{D}$ for any second-class shape is always greater than 1.0 for all supersonic and subsonic velocities. At supersonic velocities, even a sphere or a cylinder has a drag coefficient which is not appreciably less than 1.0. The physical basis for this behavior at transonic and supersonic speeds is the occurrence of a detached shock wave some distance in front of the projectile. It is known that the shock wave is detached for all projectiles except those in the first class mentioned above, for the shock wave can be attached to the (sharp) nose of the projectile only when the nose angle is less than 0 , where $\sin \theta=1 / M$ and $M=$ Mach number. All other projectiles fall in the second class and have a detached shock wave.

Assuming now that every shrapnel particle has a drag coefficient which is never less than 1.0 , it is still necessary to consider the frontal projected area of the particle, since the actual drag force, as opposed to the drag coefficient, depends on this projected area. Thus it is necessary to investigate the orientation of the shrapnel particle as it moves through the air, since the frontal projected area of any irregular shape will depend on its orientation.

In order to see how the various parameters contribute to the maximum horizontal range, we discuss the fundamental range equation A-50* derived in the Appendix:

$$
\mathbf{x}_{R}=(0.5) \mathrm{wz}_{R}
$$

with the symbol notation

$$
\begin{aligned}
x_{R} & =\text { Horizontal range }(f t) \\
z_{R} & =\text { Dimensionless factor obtained from Fig. } 1 \\
w & =\text { Relaxation distance }(f t) \text { defined by Eq A-21 }
\end{aligned}
$$

Inserting the expression for w given by Eq A-21 into Eq 1 above,

$$
\mathrm{x}_{\mathrm{R}}=(0.5) \mathrm{z}_{\mathrm{R}} \mathrm{Q( \textrm {k } ^ { - 1 } ) \mathrm { a }}
$$

with symbol notation

$$
\begin{aligned}
\mathrm{Q} & =\begin{array}{c}
\text { Average value of cosine of vector velocity angle with respect to the } \\
\text { horizontal direction }
\end{array} \\
\mathrm{k}_{\mathrm{a}}^{-1} & =\text { Characteristic distance }(\mathrm{ft}) \text { best defined by Eq A-109 }
\end{aligned}
$$

\footnotetext{
*Any formula or equation reference with the prefix " $A$ " appears in the Appendix.
} 
In Eq 2, the value of $Q$ is given by Eq A-90, which shows that it is nearly equal to the cosine of the initial angle $B$ of the projectile velocity vector with respect to the horizontal direction. Hence it is fairly accurately known in advance, for a given initial angle $B$. Referring to Fig. 1, we see that $z_{R}$ in Eq 2 is a logarithmic function of $F$. Referring to Eqs $A-68$ and $A-103$, it is evident that $F$ depends on the unknown characteristic distance $\mathrm{k}_{\mathrm{a}}^{-1}$. Since $\mathrm{x}_{\mathrm{R}}$ also depends directly on $\mathrm{k}_{\mathrm{a}}^{-1}$, as shown by $\mathrm{Eq}_{2} 2$ above, we see that the unknown characteristic distance $\mathrm{k}_{\mathrm{a}}^{-1}$ is of critical and decisive importance. Using magnitudes averaged along the entire trajectory (subscript "a"), the distance $k_{a}^{-1}$ is found to be

$$
k_{a}^{-1}=(0.167)\left(s_{a}\right)\left(C_{D}^{-1}\right)_{a}\left(\rho_{P} / \rho_{a}\right)
$$

with the notation

$$
\begin{gathered}
\rho_{\mathrm{a}}=\text { Average value of the air density }\left(\mathrm{gm} / \mathrm{cm}^{3}\right) \text { along the trajectory } \\
\rho_{\mathrm{P}}=\begin{array}{c}
\text { Density of projectile }\left(\mathrm{gm} / \mathrm{cm}^{3}\right)=\text { Specific gravity of projectile } \\
\text { relative to water }
\end{array} \\
\left(\mathrm{C}_{\mathrm{D}}^{-1}\right)_{\mathrm{a}}=\begin{array}{c}
\text { Average value of } \mathrm{C}_{\mathrm{D}}^{-1} \text { along the trajectory, where } \mathrm{C}_{\mathrm{D}} \text { is the drag } \\
\text { coefficient at any point along the trajectory (dimensionless) }
\end{array} \\
\mathrm{s}_{\mathrm{a}}=\begin{array}{c}
\text { Effective thickness (inches) of the projectile, averaged along } \\
\text { the trajectory }
\end{array}
\end{gathered}
$$

The effective thickness $s$ is defined as the projectile volume (in ${ }^{3}$ ) divided by the frontal projected area $\left(i^{2}{ }^{2}\right.$ ) which corresponds to the particular flight orientation of the projectile at the trajectory point under consideration.

From the preceding analysis it is evident that the only unknown quantity of critical importance in finding $\mathrm{k}_{\mathrm{a}}^{-1}$ is the effective thickness $\mathrm{s}$ of the projectile, as just defined. All other quantities in Eq 3 above can be fairly well estimated without detailed analysis. For example, we have just seen that the drag coefficient $C_{D}$ is never less than 1. 0, as shown by Figs. 17 and 18 in Chapter 16, of Ref 2. The drag coefficient curves of Ref 2 apply to blunt nosed projectiles moving at Mach numbers from 0.1 to 10.0 . In order to determine the effective thickness $s$ at any point along the trajectory, it is necessary to investigate the frontal projected area of the projectile corresponding to any possible orientation which may occur during its flight through the air.

The general condition for approximately stable flight of a nonrotating projectile requires that the center of mass should be well ahead of the line of action of the resultant aerodynamic drag force for at least a small range of orientations of the projectile in any direction from a zero-lift attitude. Otherwise the particular zero-lift attitude assumed is unstable, and the projectile tends to oscillate, or even tumble. For a homogeneous 
nonrotating particle having uniform density, an unstable zero-lift orientation is usually reached when the fragment presents its minimum frontal projected area. This applies especially to a thin flat sheet of material (provided the sheet is not rotating). An example of such general behavior is the wobbling flight of a falling leaf. The leaf does not move steadily in the edge-on direction, nor does it move with the flat area exactly at right angles to the flight path. Rather, its direction oscillates in an irregular way because of inherent instability. Nevertheless the average orientation more often corresponds to the maximum area presentation than it does to the edge-on presentation, at least for flat leaves. A highly curled leaf does not possess an unambiguous "flat", or "edge-on", orientation.

A thin flat sheet is in general unstable when moving edge-on through the air, since the aerodynamic lift force, at any small angle of attack, acts with a torque couple about the center of mass which tends to rotate the sheet into a position with a larger angle of attack. The larger angle of attack results in an increased torque, which tends to increase the angle of attack even further, and so forth. Thus the "leading-edge" type of flight is an unstable zero-lift orientation.

On the contrary, the perpendicular type of zero-lift orientation is at least semistable; when a flat shape moves so that the maximum frontal area is presented, there is a range of the angle of inclination within which the resulting torque is of the "restoring" variety instead of the "overturning" variety. The restoring torque (approximately cosine) is very small, which means that the flat shape may oscillate through a considerable angle before any appreciable restoring torque comes into play. Thus the slightest air flow disturbance results in directional oscillations which do not damp out readily. When the fragment turns completely over, instead of merely oscillating back and forth, a more complicated analysis is required. This is presented in the following section.

\section{Effect of Rotation}

The discussion in the preceding section applies only to a nonrotating projectile. Since a case fragment may be rotating after leaving the explosion vicinity, it is essential to estimate the effect this will produce on the maximum range distance. Let us analyze a simple type of fragment. 
Consider a uniformly thick flat plate of irregular edge outline, as diagramed below:

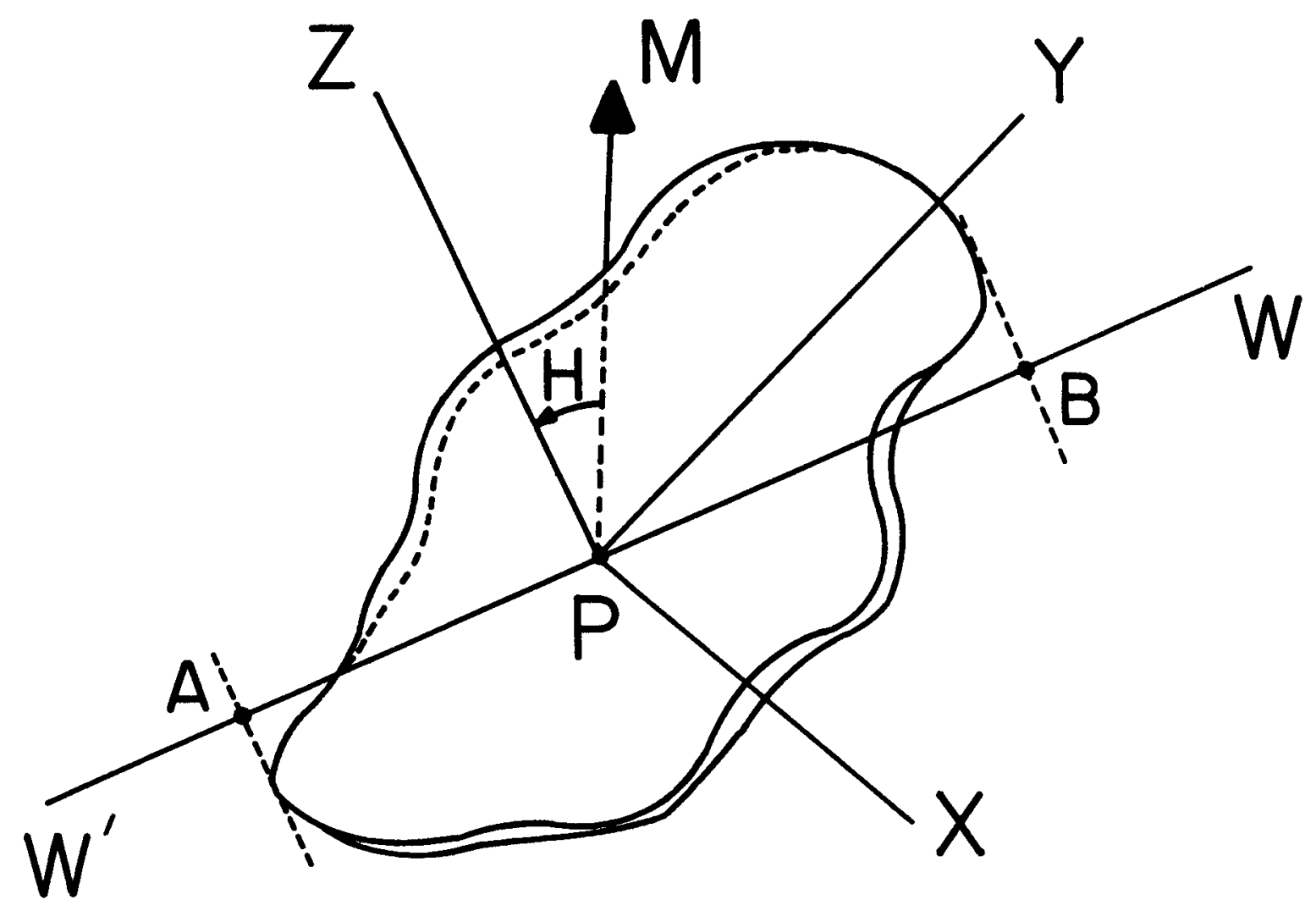

The XY plane is parallel to either face of the plate. The PZ axis is perpendicular to either face of the plate. It is not expected that all fragments will be entirely flat, as in the diagram, because bending, curling or folding may take place. These effects will be considered later, after the simplified analysis.

The most general motion of the fragment consists of a displacement of the center of mass (Point P) along the line PM, plus a rotation about the center of mass, Point $P$. The rotation can be described in terms of angular velocity components about the three principal perpendicular axes PX; PY, and PZ (fixed with respect to the fragment). The three principal axes correspond to the axes of the tensor of inertia, defined as follows: The angular momentum is defined as the product of the tensor of inertia and the angular velocity vector. The tensor of inertia is diagonalized (off-diagonal elements are zero) 
for only one orientation of a rectangular coordinate system through the center of mass. Then the three diagonal elements of the tensor of inertia are the three "principal" moments of inertia (about the axes PX, PY, and PZ, respectively).

The angular velocity component due to turning about the axis $\mathrm{PZ}$ will be called "spinning", while the resultant angular velocity about the axis PW due to turning about PX and PY will be called "tumbling". Tumbling is measured by a single angular velocity vector located along the axis $\mathrm{PW}$, somewhere in the $\mathrm{XY}$ plane, whose components are the angular velocities about the $\mathrm{PX}$ and $\mathrm{PY}$ axes, respectively.

The direction of motion PM, of the center of mass $P$, will not remain for any length of time near the XY plane (parallel to either face of the plate) because of the instability discussed in the previous section. When the direction PM of the center of mass displacement is near the XY plane, and there is appreciable "spinning" (about the axis PZ), the overturning aerodynamic torque will tend to cause precession of the total angular velocity vector.

If the spinning velocity is relatively small, we may neglect the precession, and confine our attention to the tumbling motion.

Neglecting precession, the axis $\mathrm{PW}$ tends to remain fixed in direction relative to a stationary system of coordinates, because the angular momentum direction remains nearly constant after the fragment leaves the explosion. Aerodynamic torque is zero on the average, over one complete revolution, for a flat plate, although the torque at every instant is not zero. Thus the magnitude of the angular momentum vector is subject to oscillation during the period of one complete tumbling revolution, but exhibits negligible net change per revolution.

As already mentioned, the direction of PM, the displacement of the center of mass, cannot remain permanently near the XY plane since this is an unstable configuration. Therefore we consider only the case in which the direction of PM is perpendicular to the tumbling axis $\mathrm{PW}$ which in turn is in the $\mathrm{XY}$ plane.

At any instant of time during a period of revolution (tumbling), the frontal projected area $A$ of the fragment will have a value which depends on the tumbling angle $H$ at that instant. From Eq A-1 in the Appendix, the drag force at any instant is proportional to the frontal projected area $A$, and to the drag coefficient $C_{D^{*}}$ In Fig. 29, Chapter 3, of Ref 2 it is shown that the drag coefficient $C_{D}$ of a very thin plate is practically constant, and greater than 1.0, over a wide range of inclination angles. According to Eq A-1, this implies that the actual drag force is directly proportional to the projected face area $A_{F}$ of the plate. At any instant this is equal simply to the actual face area of the plate $A_{f}$ times the cosine of the inclination angle $\mathrm{H}$. Thus 


$$
A_{F}=A_{f}(\cos H)\left(0 \leq H \leq 90^{\circ}\right)
$$

When the inclination angle $H$ is 90 degrees, the projected face area $A_{F}$ is zero. Since the plate which represents an actual shrapnel fragment has an appreciable thickness, the edge area corresponding to this thickness will produce a certain residual drag force even when the inclination angle $\mathrm{H}$ is 90 degrees. Thus it is necessary to include the projected edge area $A_{E}$ in calculating the total projected area $A$ of the plate at any instant. The total projected area $\mathrm{A}$ at any instant is

$$
A=A_{F}+A_{E}
$$

in which the projected edge area $A_{E}$ is

$$
A_{E}=A_{e} \sin H\left(0 \leq H \leq 90^{\circ}\right)
$$

and $A_{e}$ is an edge area which can be defined in terms of the rotation axis W'PW in the diagram. When the inclination angle $H$ is 90 degrees, the projected edge area $A_{E}$ is a maximum, and equal to $A_{e}$, according to Eq 6 . The maximum projected edge area $A_{e}$ is equal to the thickness of the plate times the length $A B$. The length $A B$ is the maximum extension of the plate along the rotation axis W'PW. Substituting Eqs 4 and 6 into Eq 5 ,

$$
A=A_{f} \cos H+A_{e} \sin H\left(0 \leq H \leq 90^{\circ}\right)
$$

The restriction of the inclination angle $\mathrm{H}$ to the first quadrant is required to insure that each separate area in Eq 7 remains positive. From the symmetry of the plate, in which the edge area $A_{e}$ is assumed to be perpendicular to the face area $A_{f}$, it follows that the total projected area A will vary in the same way in each of the four quadrants during one complete tumbling revolution of the plate. Thus Eq 7 can be used to obtain the projected area $A$ at any instant during a complete revolution of the plate.

Substituting the expression for A from Eq 7 into Eq A-1, the drag force $f_{H}$ at any inclination angle $\mathrm{H}$ is

$$
f_{H}=(0.5) C_{D} \rho_{a} V^{2}\left(A_{f} \cos H+A_{e} \sin H\right)
$$

in which the symbols represent

$$
\begin{aligned}
C_{D} & =\text { Drag coefficient (dimensionless) } \\
\rho_{\mathrm{a}} & =\text { Air density }\left(\mathrm{gm} / \mathrm{cm}^{3}\right)
\end{aligned}
$$




$$
\begin{aligned}
\mathrm{V} & =\text { Velocity of plate, center of mass }(\mathrm{cm} / \mathrm{sec}) \\
\mathrm{f}_{\mathrm{H}} & =\text { Drag force (dynes) }
\end{aligned}
$$

The areas $A_{e}$ and $A_{f}$ are measured in square centimeters.

If we define a thick plate shape factor $R_{E}$ (dimensionless) given by

$$
R_{E}=A_{e} / A_{f}=\frac{\text { edge area }}{\text { face area }}
$$

we may eliminate $\mathrm{A}_{\mathrm{e}}$ in $\mathrm{Eq} 8$ and obtain

$$
f_{H}=(0.5) C_{D}{ }_{a} V^{2} A_{f}\left(\cos H+R_{E} \sin H\right)
$$

Solving $\mathrm{Eq} \mathrm{A}-4$ for A gives

$$
A=2 k m\left(\rho_{a} C_{D}\right)^{-1}
$$

In Eq 11, define $k=k_{f}$ when $A=A_{f}$. Then

$$
A_{f}=2 k_{f} m\left(\rho_{i} C_{D}\right)^{-1}
$$

Substituting the value of $\mathrm{A}_{\mathrm{f}}$ from Eq 12 into Eq 10 gives

$$
f_{H}=k_{f} m V^{2}\left(\cos H+R_{E} \sin H\right)
$$

with symbol designation

$$
\begin{aligned}
\mathrm{m} & =\text { Mass of plate }(\mathrm{gm}) \\
\mathrm{k}_{\mathrm{f}} \text { or } \mathrm{k} & =\text { Air drag parameter defined by Eqs A-4 and A-3'}
\end{aligned}
$$

The air drag parameter $\mathrm{k}$ has the dimension of reciprocal length, and is the same $\mathrm{k}$ previously appearing as characteristic distances $\mathrm{k}^{-1}$ or $\mathrm{k}_{\mathrm{a}}^{-1}$, noted in connection with Eqs 2 and 3.

Assuming a uniform speed of rotation, in which the period of one complete revolution is equal to $\mathrm{T}$ seconds, the inclination angle $\mathrm{H}$ at any instant of time $\mathrm{t}$ is found from

$$
\mathrm{H}_{(\text {degrees })}=360^{\circ}(\mathrm{t} / \mathrm{T})
$$

or

$$
H_{(\text {radians })}=(6.28)(t / T)
$$


The total drag impulse given to the plate during a complete revolution is four times the impulse given in one quarter of a revolution, because the projected area varies in the same way with respect to $\mathrm{H}$ in each of the four quadrants. Therefore the average drag force can be found from the impulse I given to the plate during one quarter of a complete period of revolution, $\mathrm{T} / 4$. The impulse for one quarter of a period is

$$
\mathrm{I}=\int_{0}^{\mathrm{T} / 4} \mathrm{f}_{\mathrm{H}} \mathrm{dt}
$$

Therefore, from Eqs 13 and 15, after eliminating $H$ through Eq 14, the impulse I is

$$
I=k_{f} m V^{2} \int_{0}^{T / 4}\left[\cos (6.28 t / T)+R_{E} \sin (6.28 t / T)\right] d t
$$

which is equal to

$$
I=(2 / \pi) k_{f} m v^{2}\left(1+R_{E}\right)(T / 4)
$$

The drag impulse $I$ is defined in terms of the average force $f_{r}$ during one quarter of a period of revolution

$$
I=(T / 4) f_{r}
$$

Using the value of I from Eq 17, Eq 16 becomes

$$
f_{r}=(1.57)^{-1} k_{f} m V^{2}\left(1+R_{E}\right)
$$

If we consider a nontumbling plate which may oscillate slightly, the average projected area $A$ is approximately equal to the face area $A_{f}$. In this case we set $A=A_{f}$ in Eq A-1 and eliminate $A_{f}$, using Eq 12, which gives

$$
\begin{gathered}
f_{f}=k_{f} m v^{2} \\
\text { (nontumbling) }
\end{gathered}
$$

We can also obtain the same result by simply letting $\mathrm{H}=0$ in Eq 13 . Dividing Eq 18 by Eq 19, we obtain

$$
f_{r} / f_{f}=(1.57)^{-1}\left(1+R_{E}\right)
$$


Equation 20 shows the ratio of the average "tumbling" rotational drag force $f_{r}$ to the drag force $f_{f}$ on a nontumbling plate.

In order to correct the horizontal range when the plate is tumbling, it is only necessary to correct the characteristic distance $k_{f}^{-1}$ which corresponds to a nontumbling plate. From Eq 19,

$$
k_{f}^{-1}=\left(m V^{2}\right) f_{f}^{-1}
$$

If we define a new characteristic distance $\mathrm{k}_{\mathrm{r}}^{-1}$ for the tumbling rotational case, Eq 21 becomes

$$
\mathrm{k}_{\mathrm{r}}^{-1}=\left(\mathrm{mV}^{2}\right) \mathrm{f}_{\mathrm{r}}^{-1}
$$

Dividing Eq 22 by Eq 21

$$
\frac{k_{r}^{-1}}{k_{f}^{-1}}=f_{f} / f_{r}
$$

Substituting the value of $f_{f} / f_{r}$ from Eq 20 into Eq 23 gives

$$
\frac{k_{r}^{-1}}{k_{f}^{-1}}=(1.57)\left(1+R_{E}\right)^{-1}
$$

in which $\mathrm{k}_{\mathrm{r}}^{-1}$ is the corrected value of $\mathrm{k}_{\mathrm{f}}^{-1}$ that must be used when the fragment is tumbling during flight. The value of $\mathrm{k}_{\mathrm{f}}$ is the same as the value of $\mathrm{k}$ in Eq A-4 with A replaced by $A_{f}$. Note that $R_{E}$ is defined by Eq 9. Equation 24 may also be considered to represent the ratio of the face area to the average projected area of the tumbling plate.

In Eq 24, the correction factor $\mathrm{k}_{\mathrm{r}}^{-1} / \mathrm{k}_{\mathrm{f}}^{-1}$ has its largest value, namely 1.57, when $R_{E}=0$. Clearly, the shape corresponding to a vanishingly small $R_{E}$ is an "infinitely thin" plate. When $R_{E}=1.0$ the edge area $A_{e}$ is equal to the face area $A_{f}$ as follows from Eq 9. A well-known example of such a regular solid is the cube. The square bar is another example of special symmetry in which $R_{E}=1.0$ provided the tumbling axis $\mathrm{PW}$ is parallel to the longer dimension, as in the diagram.

Numerous examples of polygonal plates could be given, in which the effective edge area is equal to the face area. Note, however, that Eq 24 applies to any flat plate, no 
matter what value of $R_{E}$ corresponds to it, and the plate does not need to be polygonal. A "flat" plate, by definition, has at least two equal and parallel face areas.

In Eq 24 the minimum value of $k_{r}^{-1} / k_{f}^{-1}$, namely 0.785 , is reached when $R_{E}=1.0$, because no larger value of $R_{E}$ can occur for any type of fragment. If one considered a "mathematical" value of $R_{E}^{\prime}$ greater than 1.0 , it is evident that it would correspond physically to a shape with $\left(R_{E}^{\prime}\right)^{-1}=R_{E}$ in which $\left(R_{E}^{\prime}\right)^{-1}$ is less than 1. 0. An "edge-area" greater than a "face-area" has no meaning in terms of the thickness factor $R_{E}$; ie, the . edge-area must always be less than the face-area, by definition.

Some things should be said concerning the most probable values for $R_{\mathrm{E}}$ in an actual explosion, in which fragments are produced by rupturing a metal case. On general principles, one can be sure that the maximum dimension of any fragment will be less than the radius of the container surrounding the explosive charge, for such devices as bombs or depth charges. Of course, when an explosive charge is not "closely" contained or when large asymmetries exist, the fragments may be larger. The largest shrapnel fragment from a "closely-cased" bomb will, therefore, have a face area and an edge area which correspond to an $R_{E}$ value, from $E q$ 9, considerably greater than zero. The most probable value of $R_{E}$ is a statistical quantity that can only be found by observing a large number of fragments from many bomb explosions involving the same type of container. The "median" of $R_{E}$ is 0.50 , which is half way between the extreme values; but this is not necessarily the most probable value of $R_{E^{*}}$. This could be true only if all values of $R_{E}$ were symmetrically distributed on both sides of the 0.5 value. As a rough estimate, until further information is available, one may take $R_{E}=0.25$ as a "probable minimum". This corresponds to a realistic "probable maximum" range, since the $R_{E}$ term appears in the denominator of the right side of Eq 24 from which the corrected characteristic distance $\mathrm{k}_{\mathrm{r}}^{-1}$ is reckoned.

The maximum-range curves plotted in Fig. 4 cover (by interpolation) all the possible magnitudes of $R_{E}$ from zero to 1.0 . Therefore, these range curves are universal, and can be used to make more accurate range predictions whenever there is more information available concerning most probable $R_{E}$ values that correspond to actual fragments from various types of explosions.

\section{Maximum Missile Ranges}

The procedure for calculating the maximum range of a projectile can be developed simply from the characteristic-distance Eq 3 in conjunction with the rotation correction factor just derived in Eq 24. Taking average values along the trajectory (subscript a) the corrected characteristic distance is determined from Eq 24. 


$$
\left(k_{r}^{-1}\right)_{a}=(1.57)\left(k_{f}^{-1}\right)_{a}\left(1+R_{E}\right)^{-1}
$$

in which $\left(\mathrm{k}_{\mathrm{r}}^{-1}\right)$ is the corrected value of $\left(\mathrm{k}_{\mathrm{f}}^{-1}\right)$ due to (tumbling) rotation, and $\left(\mathrm{k}_{\mathrm{f}}^{-1}\right)$ is defined by an equation similar to Eq 3, but with A replaced by $A_{f}$. See Eqs 12, 18, and 19 above.

$$
\left(\mathrm{k}_{\mathrm{f}}^{-1}\right)_{\mathrm{a}}=(0.167)\left(\mathrm{s}_{\mathrm{f}}\right)\left(\mathrm{C}_{\mathrm{D}}^{-1}\right)_{\mathrm{a}}\left(\rho_{\mathrm{P}} / \rho_{\mathrm{a}}\right)
$$

(nontumbling fragment)

Equation 26 is identical to Eq 3 except that $s_{a}$ is replaced by $s_{f}$. The quantity $s_{f}$ is defined as the fragment (flat-plate) volume divided by the face area $A_{f}$. Thus $s_{f}$ is the same as the quantity $s_{a}$ with A replaced by $A_{f}$. Therefore, $s_{f}$ is constant and is practically equal to the case thickness $s$ (measured in inches), unless the fragment is bent or curled. Bent or curled fragments are considered in the next section. Equation 26 gives the value of $\mathrm{k}^{-1}$ from Eq A-109 averaged along the trajectory, which results in Eq 3 with subscript a, and also with the variable projected area $A$ replaced by the constant face area $A_{f}$. Hence the subscript $f$ appears in Eq 26 which refers to a nontumbling fragment.

Substituting the expression for $\left(\mathrm{k}_{\mathrm{f}}^{-1}\right)$ from Eq 26 into Eq 25 we obtain the characteristic distance $\left(\mathrm{k}_{\mathrm{r}}^{-1}\right)_{\mathrm{a}}$ for a rotating (tumbling) projectile

$$
\begin{gathered}
K=(0.262)\left(s_{f}\right)\left(C_{D}^{-1}\right)_{a}\left(\rho_{P} / \rho_{a}\right)\left(1+R_{E}\right)^{-1} \\
K=\left(k_{r}^{-1}\right)_{a}
\end{gathered}
$$

by definition.

The general method for calculating a typical maximum horizontal range distance $\left(x_{R}\right)$ is illustrated in Tables I and II. The various steps in the calculation proceed from column to column in each table according to the following schedule. 


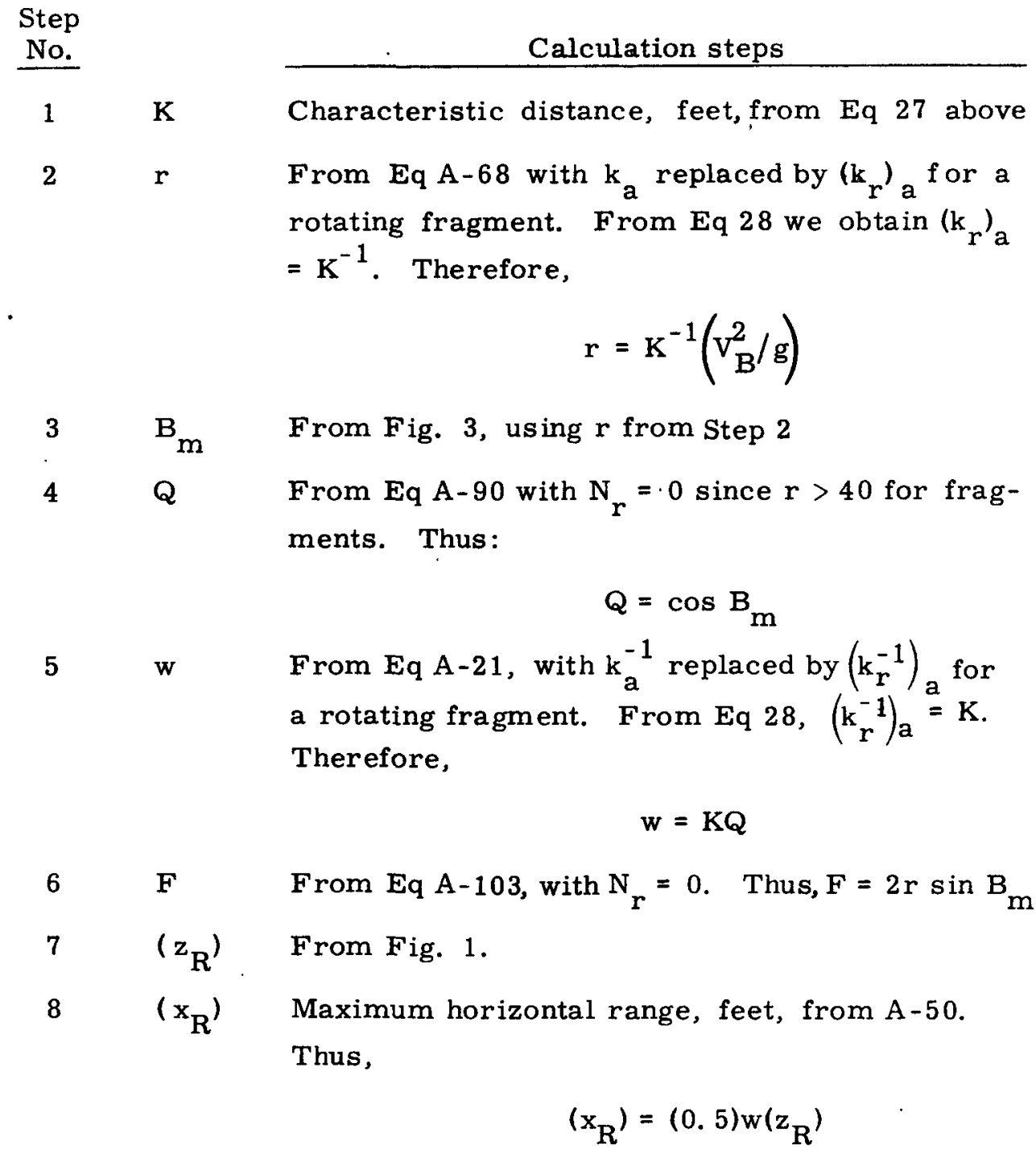

Definitions of all symbols involved in the above steps are given in the Appendix in connection with the equations located there.

In order to carry out all the steps it is necessary to know the magnitudes of the following quantities:

\footnotetext{
$s_{f} \quad \frac{\text { Fragment volume }}{\text { Face area }}=$ Effective fragment thickness (inches)

$\left(\mathrm{C}_{\mathrm{D}^{\prime}}{ }_{\mathrm{a}}\right.$ Drag coefficient, averaged along the trajectory (dimensionless)

$\rho_{\mathrm{P}} \quad$ Projectile density $\left(\mathrm{gm} / \mathrm{cm}^{3}\right)$, numerically equal to the specific gravity relative to water

$\rho_{\mathrm{a}} \quad$ Air density $\left(\mathrm{gm} / \mathrm{cm}^{3}\right)$, averaged along the trajectory

$R_{E} \quad$ Dimensionless shape factor, Edge area
} 


\section{$\mathrm{V}_{\mathrm{B}} \quad$ Initial speed of fragment $(\mathrm{ft} / \mathrm{sec})$ \\ g Acceleration due to gravity, $32 \mathrm{ft} / \mathrm{sec}$}

Values assumed for these quantities are as follows:

$$
\begin{array}{rl}
\mathrm{V}_{\mathrm{B}} & 10,000 \mathrm{ft} / \mathrm{sec} \\
\left(\mathrm{C}_{\mathrm{D}}\right)_{\mathrm{a}} & 1.0 \\
\mathrm{R}_{\mathrm{E}} & \text { Assigned } 0.0,0.25,0.50,0.75 \text {, and } 1.0 \\
\rho_{\mathrm{P}} & 2.7 \text { for aluminum, or } 7.8 \text { for steel } \\
\mathrm{s}_{\mathrm{f}} & \text { Assigned values from } 0.5 \text { to } 10.0 \text { inches } \\
& \rho^{-1}=(773)\left(\mathrm{p}_{\mathrm{o}} / \mathrm{p}\right)\left(1+\frac{\mathrm{deg} . \mathrm{C}}{273}\right)^{*}
\end{array}
$$

in which

$$
\begin{aligned}
\rho^{-1}= & \text { Air specific volume, } \mathrm{cm}^{3} / \mathrm{gm}, \text { at a barometric pressure of } \\
& \mathrm{p} \text { inches of mercury (for dry air) } \\
\mathrm{p}_{\mathrm{O}}= & 29.92 \text { inches of mercury }
\end{aligned}
$$

For use in the Coyote Canyon test field (Sandia facility), the specific volume (Eq 29) should be evaluated at a barometric pressure which corresponds to the average altitude of a shrapnel fragment trajectory. This average altitude is taken to be 7500 feet above sea level, at which the barometric pressure $p$ is about 22.65 inches of mercury, according to the NACA Standard Atmosphere. ${ }^{3}$ The maximum temperature is arbitrarily assumed to be $30^{\circ} \mathrm{C}$ (in the summer). With these values $\mathrm{Eq} 29$ gives the air specific volume $\rho_{\mathrm{a}}^{-1}$, averaged along the trajectory,

$$
\rho_{\mathrm{a}}^{-1}=(1.13)\left(10^{3}\right) \mathrm{cm}^{3} / \mathrm{gm}
$$

By Eq 27, the characteristic distance $K$ is directly proportional to $\rho_{a}^{-1}$, and therefore $\mathrm{K}$ is directly proportional to the absolute air temperature by Eq 29 . In order to be on the safe side in estimating missile ranges, one should choose an air temperature which is as high as ever expected to occur at 7500 feet altitude. This has been assumed as $30^{\circ} \mathrm{C}$ $\left(86^{\circ} \mathrm{F}\right)$. There is also a range of possible barometric pressures, but this small percentage

\footnotetext{
From Ref 3, page 2001.
} 
variation has been neglected in deriving the value $\rho_{a}^{-1}=(1.13)\left(10^{3}\right) \mathrm{cm}^{3} / \mathrm{gm}$ as the specific volume of air to be used in fragment range calculations.

\section{TABLE I}

Initial angle for maximum range of aluminum fragments moving at $10,000 \mathrm{ft} / \mathrm{sec}$, assuming: The shape factor $R_{E}=0.25$, Air specific volume $\rho_{a}^{-1}=1.13\left(10^{3}\right) \mathrm{cm}^{3} / \mathrm{gm}$, and $C_{D}=1.0$

\section{Effective fragment thickness}

$\mathrm{s}_{\mathrm{f}}$

(in)

0.5

1.0

1.5

2. 0

3. 0

4. 0

5. 0

6. 0

7. 0

8. 0

10. 0

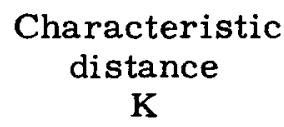

(ft)

\begin{tabular}{r}
$(\mathrm{ft})$ \\
\hline 320 \\
640 \\
960 \\
1280 \\
1920 \\
2560 \\
3200 \\
3840 \\
4480 \\
5120 \\
6400
\end{tabular}

Air

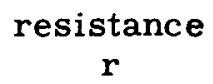

$\left(g^{\prime} s\right)$

9740

4870

3250

2440

1620

1220

975

812

695

610

487
Angle for maximum

range

$\mathrm{B}_{\mathrm{m}}$

(deg.)

17. 5

18. 0

18. 2

18. 5

19.0

19. 3

19. 7

20. 0

20. 1

20.2

20.5

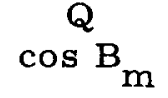

$\underline{\text { (dimensionless) }}$

0.95

0.95

0.95

0.95

0.95

0.94

0.94

0.94

0.94

0.94

0.94

TABLE II

Maximum range of aluminum fragments moving at $10,000 \mathrm{ft} / \mathrm{sec}$

$$
R_{E}=0.25, \rho_{a}^{-1}=(1.13)\left(10^{3}\right) \mathrm{cm}^{3} / \mathrm{gm}, C_{D}=1.0
$$

\begin{tabular}{|c|c|c|c|c|}
\hline $\begin{array}{c}\text { Effective } \\
\text { fragment } \\
\text { thickness } \\
\mathrm{s}_{\mathrm{f}} \\
(\mathrm{in}) \\
\end{array}$ & $\begin{array}{c}\text { Relaxation } \\
\text { distance } \\
\text { w } \\
\text { (ft) } \\
\end{array}$ & $\begin{array}{c}\text { Acceleration } \\
\text { ratio } \\
F \\
\text { (dimensionless) }\end{array}$ & $\begin{array}{c}\text { Distance } \\
\text { ratio } \\
\mathbf{z}_{\mathbf{R}} \\
\text { (dimensionless) } \\
\end{array}$ & $\begin{array}{c}\text { Maximum } \\
\text { horizontal } \\
\text { range } \\
\mathrm{x}_{\mathrm{R}} \\
(\mathrm{ft}) \\
\end{array}$ \\
\hline 0.5 & 304 & 5820 & 11.1 & 1,690 \\
\hline 1. 0 & 608 & 3020 & 10.3 & 3,140 \\
\hline 1.5 & 910 & 2020 & 9.9 & 4,500 \\
\hline 2.0 & 1220 & 1550 & 9.6 & 5,850 \\
\hline 3. 0 & 1820 & 1050 & 9.2 & 8,350 \\
\hline 4. 0 & 2400 & 805 & 8.9 & 10,700 \\
\hline 5.0 & 3000 & 660 & 8.7 & 13,100 \\
\hline 6.0 & 3600 & 552 & 8.5 & 15,300 \\
\hline 7. 0 & 4200 & 480 & 8. 3 & 17,400 \\
\hline 8. 0 & 4800 & 427 & 8.2 & 19,700 \\
\hline 10.0 & 6000 & 340 & 8.0 & 24,000 \\
\hline
\end{tabular}




\section{Ranges of Irregular Fragments}

The results of Table II and of similar calculations are plotted as curves in Fig. 4 for aluminum and steel fragments. The maximum ranges are given in terms of the fundamental parameter $s_{f}$, the "effective" fragment thickness, measured in inches. Each curve corresponds to a fragment of a certain shape as indicated by a fixed value of the shape factor $R_{E^{*}}$ A relatively thin flat fragment corresponds to $R_{E} \cong 0$. A cube corresponds to $R_{E}=1.0$, and intermediate shapes have intermediate $R_{E}$ magnitudes.

It must be emphasized that the "effective" thickness $s_{f}$, used in Fig. 4 , is not in general equal to the container thickness $\mathrm{S}$ unless the fragment is approximately a flat plate.

When the fragment consists of a bent, curled, or folded plate, the previous definitions must be extended in order to estimate the corresponding range distances. The effective fragment thickness $s_{f}$ has been defined previously as

where

$$
s_{f}=v_{f} / A_{f}
$$

where

$$
\begin{aligned}
& s_{f}=\text { Effective thickness (inches) } \\
& V_{f}=\text { Fragment volume }\left(\mathrm{in}^{3}\right) \\
& A_{f}=\text { Face area }\left(\mathrm{in}^{2}\right)
\end{aligned}
$$

For a flat plate, the face area $A_{f}$ is unambiguous, but the "face area" $A_{f}$ of a bent, curled, or folded plate is as yet undefined, and has no meaning. In order to extend the definition, we refer to Eq 7, which gives the frontal projected area $A$ in terms of the two areas $A_{e}$ and $A_{f}$. From Eq 7, it is clear that the "edge-area" $A_{e}$ is the minimum frontal projected area, and this minimum occurs when the inclination angle $\mathrm{H}$ is equal to 90 degrees. This conclusion applies as yet only to a flat plate. By analogy, let us define $\mathrm{A}$ as the minimum frontal projected area of a bent, curled, or folded plate, and let us choose the angle $\mathrm{H}$ so that $\mathrm{H}$ is 90 degrees when the bent, curled, or folded plate presents its minimum frontal projected area. Then, in order to preserve the form of $\mathrm{Eq} 7$, we define $\mathrm{A}_{\mathrm{f}}$ as the frontal projected area of the bent, curled, or folded plate when the inclination angle $H$ is zero. Obviously this occurs when the fragment has turned 90 degrees from the position where it presented its minimum frontal projected area, defined as $A_{e}$. It follows from this extended definition that the generalized "face area" $A_{f}$ is always approximately equal to the maximum frontal projected area of the fragment.

Using the extended definitions of $\mathrm{A}_{e}$ and $\mathrm{A}_{\mathrm{f}}$, derived above, we can calculate the values of $s_{f}$ and $R_{E}$ for a bent, curled, or folded fragment, using Eqs 30 and 9, respectively. The ranges are then obtained from Fig. 4 using the values of $s_{f}$ and $R_{E}$ so obtained. 


\section{Results and Discussion}

It is of interest to compare the range predictions of the present report with the ranges predicted by the cube root formula

$$
\text { Range in feet }=(600)(\text { charge wt. })^{1 / 3}
$$

where charge wt $=$ pounds of TNT equivalent. A missile from a 250 -pound TNT equivalent explosive charge was observed to land at 5500 feet. According to the cube root, Eq 31 , the corresponding explosive charge should have been at least 780 pounds.

The missile in question consists of a 3/8-inch steel plate folded so that the actual face area $A_{f}$ is only about (0.55) times the "unfolded" flat plate face area, which we designate as $A_{f}^{\prime}$. The effective thickness $s_{f}$ is derived from $E q 30$ by substituting the relation

$$
A_{f}=(0.55) A_{f}^{\prime}
$$

Eliminating $A_{f}$ from Eq 30 by using Eq 32,

$$
s_{f}=(0.55)^{-1} V_{f}\left(A_{f}^{\prime}\right)^{-1}=(0.55)^{-1} S
$$

But $\mathrm{V}_{f}\left(\mathrm{~A}_{\mathrm{f}}^{\prime}\right)^{-1}$ is simply equal to the "flat plate" thickness designated as $\mathrm{S}$ in Eq 33 above. This is also the container thickness. Since $S$ is equal to $3 / 8$ inch in the present instance, we obtain the effective fragment thickness,

$$
s_{f}=(0.55)^{-1}(3 / 8)=0.68 \text { inch }
$$

The fragment has a shape corresponding to an $R_{E}$ value of about 0.25 . Using $R_{E}=0.25$ and $s_{f}=0.68$ inch, from Eq 34, the predicted maximum range is obtained as 5750 feet, by using Fig. 4.

This prediction assumes a maximum initial fragment speed of $10,000 \mathrm{ft} / \mathrm{sec}$, which would always be nearly reached when the explosive charge weight is greater than the case weight.

Note that the explosive charge weight does not appear in Fig. 4. Also it should be pointed out that the curves in Fig. 4 refer to the range of a projectile which starts off at the optimum initial angle with respect to the horizontal direction, at which the maximum possible range occurs for a given initial velocity. It will now be shown that the explosive charge weight has an appreciable effect on the maximum horizontal range only when the 
charge weight is much smaller than the case weight. The formula given in Ref 1 for TNT charges is

$$
\text { initial missile velocity } \mathrm{ft} / \mathrm{sec}=(6940)(0.5+\mathrm{R})^{-\frac{1}{2}}
$$

in which

$$
R=\frac{\text { Case weight }}{\text { Charge weight }(\mathrm{TNT})} \text {. }
$$

Note that the Gurney energy-density constant $(2 E)^{1 / 2}$ is $6940 \mathrm{ft} / \mathrm{sec}$ for TNT. As an example, let us assume that the charge weight is equal to the case weight. Then by definition

$$
R=1.0
$$

and the corresponding initial missile velocity from Eq 35 is $5670 \mathrm{ft} / \mathrm{sec}$. In order to see what effect this would have on the maximum range we refer to the eight steps of the calculation schedule preceding Table I. The figures to be used in Step 1, Eq 27, are

$$
\begin{array}{rl}
\mathrm{s}_{\mathrm{f}} & 0.68 \text { inch, effective fragment thickness } \\
\left(\mathrm{C}_{\mathrm{D}}\right)_{\mathrm{a}} & 1.0 \text {, drag coefficient } \\
\rho_{\mathrm{P}} & 7.8 \text {, density of steel } \\
\rho_{\mathrm{a}}^{-1} & 1.13\left(10^{3}\right) \mathrm{cm}^{3} / \mathrm{gm} \text {, specific volume of air at } 7500 \mathrm{ft} \\
\mathrm{R}_{\mathrm{E}} & 0.25, \text { shape factor } \\
\mathrm{V}_{\mathrm{B}} & 10,000 \mathrm{ft} / \mathrm{sec} \text {, and also } \\
\mathrm{V}_{\mathrm{B}} & 5670 \mathrm{ft} / \mathrm{sec}
\end{array}
$$

The above values refer to the actual fragment which landed at a distance of 5500 feet.

These values also refer to the graph $\left(\mathrm{R}_{E}=0.25\right)$ in Fig. 4 for a steel fragment moving initially at 10,000 feet per second. Thus the list of eight steps below serves a double purpose. First, it shows how the maximum horizontal range of a projectile is affected by a change in the initial speed. Second, it shows the derivation of a graph in Fig. 4 which is not included in Table I or II. 
The eight steps in the calculation of each initial speed are:

\begin{tabular}{lll} 
& \multicolumn{1}{c}{$\mathrm{V}_{\mathrm{B}}=10,000$} & \multicolumn{1}{c}{$\mathrm{V}_{\mathrm{B}}=5670$} \\
$\mathrm{~K}$ & $1260 \mathrm{ft}$ & $1260 \mathrm{ft}$ \\
$\mathrm{r}$ & 2480 & 797 \\
$\mathrm{~B}_{\mathrm{m}}$ & 18.5 degrees & 20.0 degrees \\
$\mathrm{Q}$ & 0.94 & 0.94 \\
$\mathrm{w}$ & $1185 \mathrm{ft}$ & $1185 \mathrm{ft}$ \\
$\mathrm{F}$ & 1570 & 545 \\
$\mathrm{z}_{\mathrm{R}}$ & 9.65 & 8.5 \\
$\mathrm{x}_{\mathrm{R}}$ & $5720 \mathrm{ft}$ & $5040 \mathrm{ft}$
\end{tabular}

When the weight of the explosive is equal to the case weight, we see that the 43 percent reduction in initial speed $V_{B}$ changes the horizontal range from 5720 to 5040 feet which is only a 12-percent reduction from the limiting value for large charge weights. The corresponding change in optimum direction angle $\mathrm{B}_{\mathrm{m}}$ is from 18.5 degrees to 20 degrees, which is only an 8 -percent increase. These results directly indicate that a negligible reduction in the missile range occurs even when the explosive charge weight is as small as the case weight. If the charge weight is much less than the case weight, one should carry out additional calculations similar to those just given in order to make a significant downward revision of the safe missile ranges given in Fig. 4, which are the limit values approached when the explosive charges are very large.

Although the maximum ranges in Fig. 4 were necessarily determined only for the optimum initial direction angle $\left(B=B_{m}\right)$ for each projectile, it can be shown that the corresponding ranges for other direction angles are not appreciably reduced unless the direction angles in question are much less or much greater than the optimum for each fragment. Thus there is a large solid angle surrounding the explosion, through which many fragments will travel out to large distances, nearly as great as the maximum ranges which are given in Fig. 4.

To prove this statement, we calculate the range corresponding to

$$
\begin{gathered}
\mathrm{V}_{B}=10,000 \mathrm{ft} / \mathrm{sec} \\
\text { and } \\
B=5 \text { degrees }
\end{gathered}
$$

for the same shrapnel fragment as before. The eight steps of this calculation are the same as the eight steps of the preceding calculation (in the $V_{B}=10,000$ column), except that 
$B_{m}=18.5$ degrees is replaced by $B=5$ degrees. Thus we obtain in this instance

$\begin{array}{llll}\mathrm{K} & 1260 \mathrm{ft} & \mathrm{r} & 2480 \\ \mathrm{~B} & 5 \mathrm{degrees} & \mathrm{Q} & 0.996 \\ \mathrm{w} & 1255 \mathrm{ft} & \mathrm{F} & 433 \\ \mathrm{z}_{\mathrm{R}} & 8.2 & \mathrm{x}_{\mathrm{R}} & 5150 \mathrm{ft}\end{array}$

We see that the range 5150 feet when $B=5$ degrees is a reduction of 10 percent from the range 5720 feet corresponding to the optimum direction angle $B=18.5$ degrees. This is nearly the same as the 12 -percent reduction already calculated for the reduced initial speed $5670 \mathrm{ft} / \mathrm{sec}$. This shows that missiles can leave the explosion at any angle between 5 and 18.5 degrees and still travel nearly all the way out to the distance 5720 feet corresponding to 18.5 degrees. (The distance 5720 feet is also the one given in Fig. 4.)

A further calculation shows that the direction angle $B$ can be considerably greater than 18.5 degrees (for the fragment under consideration) before the range drops by as much as 10 percent, and it is evident that similar calculations may be made for all the ranges indicated by the graphs in Fig. 4.

Finally, it may be of some interest to show to what extent the cube root range, Eq 31, is supported by the theory derived in this report. First of all, if the case weight is always the same proportion of the explosive charge weight, a geometric analysis (based on constant density) shows that the case thickness must vary as the cube root of the charge weight. The cube root formula, Eq 31, would then be valid, provided the range were simply proportional to the case thickness S. When the curves of Fig. 4 are plotted on ordinary graph paper instead of on logarithmic graph paper it is found that the relation between the "effective" fragment thickness $s_{f}$ and the range is almost a straight line. If the plot in each case were exactly a straight line, the trend of the cube root law Eq 31 would be exactly confirmed (at least for high-speed fragments). It is evident that in general the case weight is not always the same fraction of the charge weight. Therefore, Eq 31 can not be correct for all types of explosions, because a different multiplying factor would be required for each different ratio $\mathrm{R}$ of the case weight to the explosive charge weight, even neglecting the effect of folding or curling of the fragments (which results in fragments which have effective thicknesses different from the case thickness).

\section{Conclusions}

1. When the explosive charge weight is greater than the case weight, the $\max -$ imum horizontal range is obtained from Fig. 4. This range depends only on the assumed size and shape of a fragment. 
2. When the explosive charge weight is much less than the case weight, the range of a fragment is significantly less than that shown in Fig. 4 and depends on the charge weight as well as on the fragment geometry. The method of calculation is explained in the report.

3. Since cube root scaling is relatively correct, approximate distances (neglecting exact fragment geometry), can be found by using the cube roots of the different charge weights (pounds), with a single constant multiplying factor of 600 feet. More accurate distances must be obtained from a set of different multiplying factors. These multiplying factors can be found only by using the methods summarized in conclusions 1 and 2 above, supplemented by actual experience with various types of explosions. 


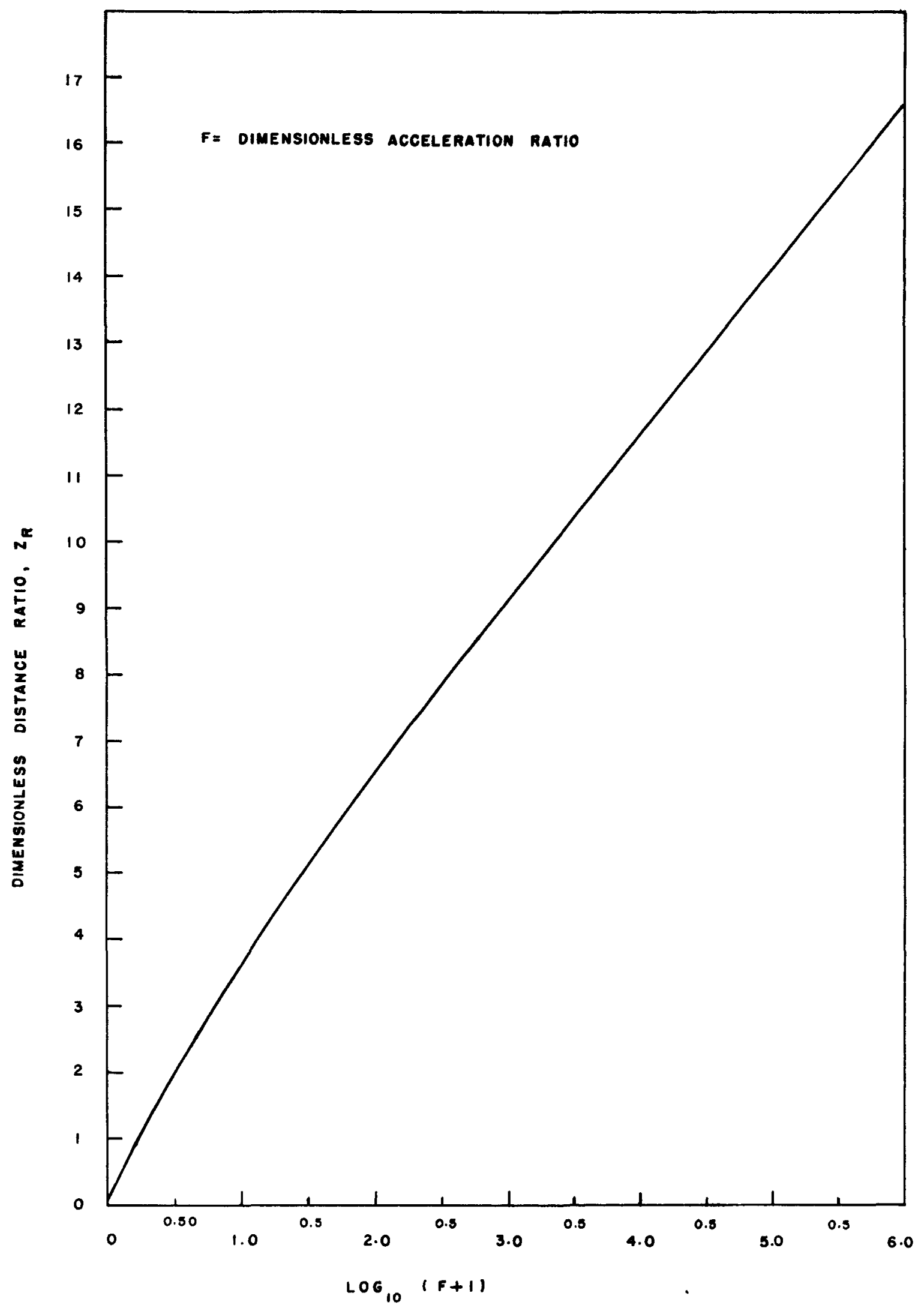

Fig. 1 - - Solution of range equation A-49, wide range of $z_{R}$ 


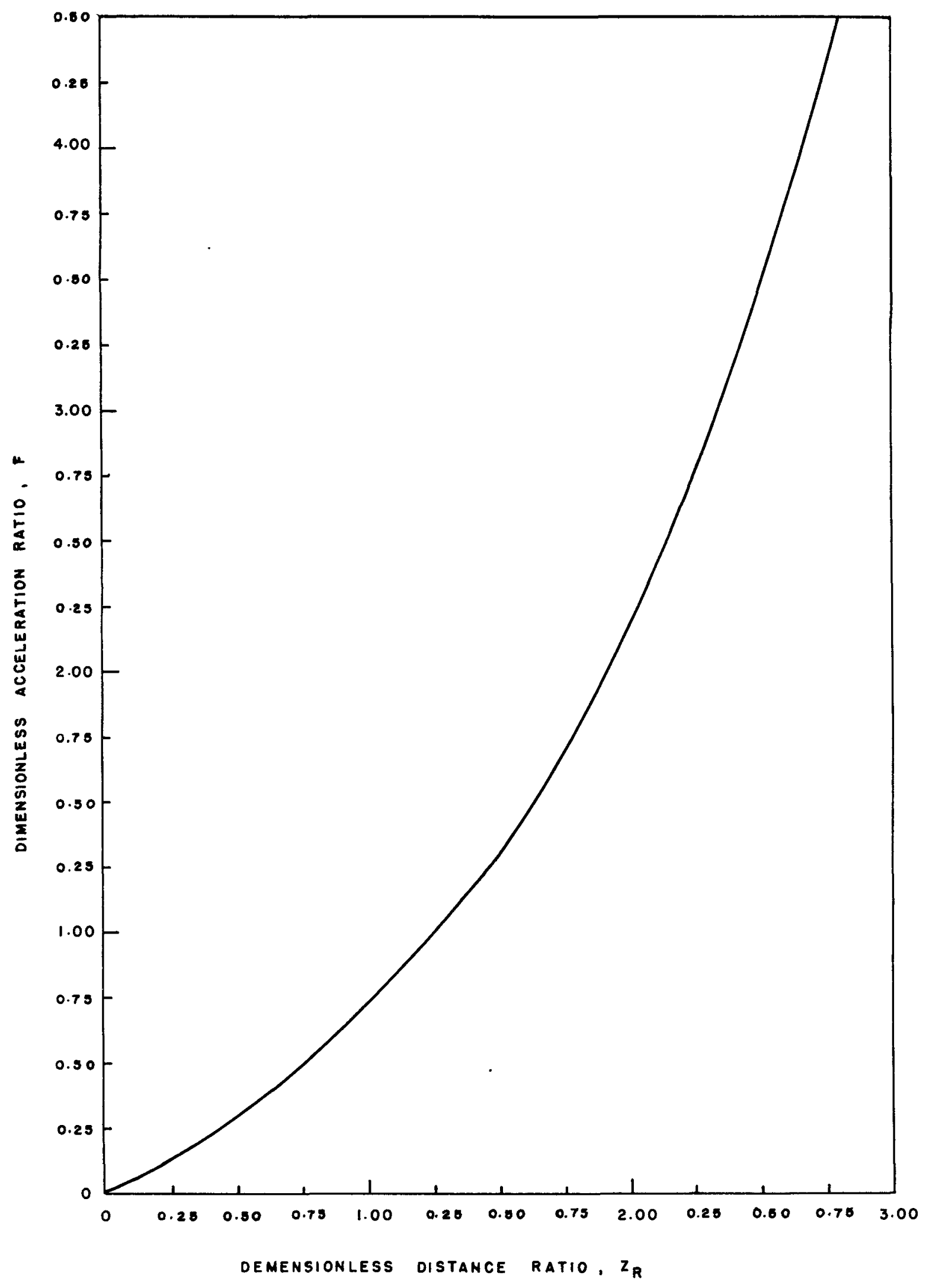

Fig. 2 -- Solution of range equation A-49, small values of $z_{R}$ 
$r=$ INITIAL AIR RESISTANCE IN $g$ UNITS

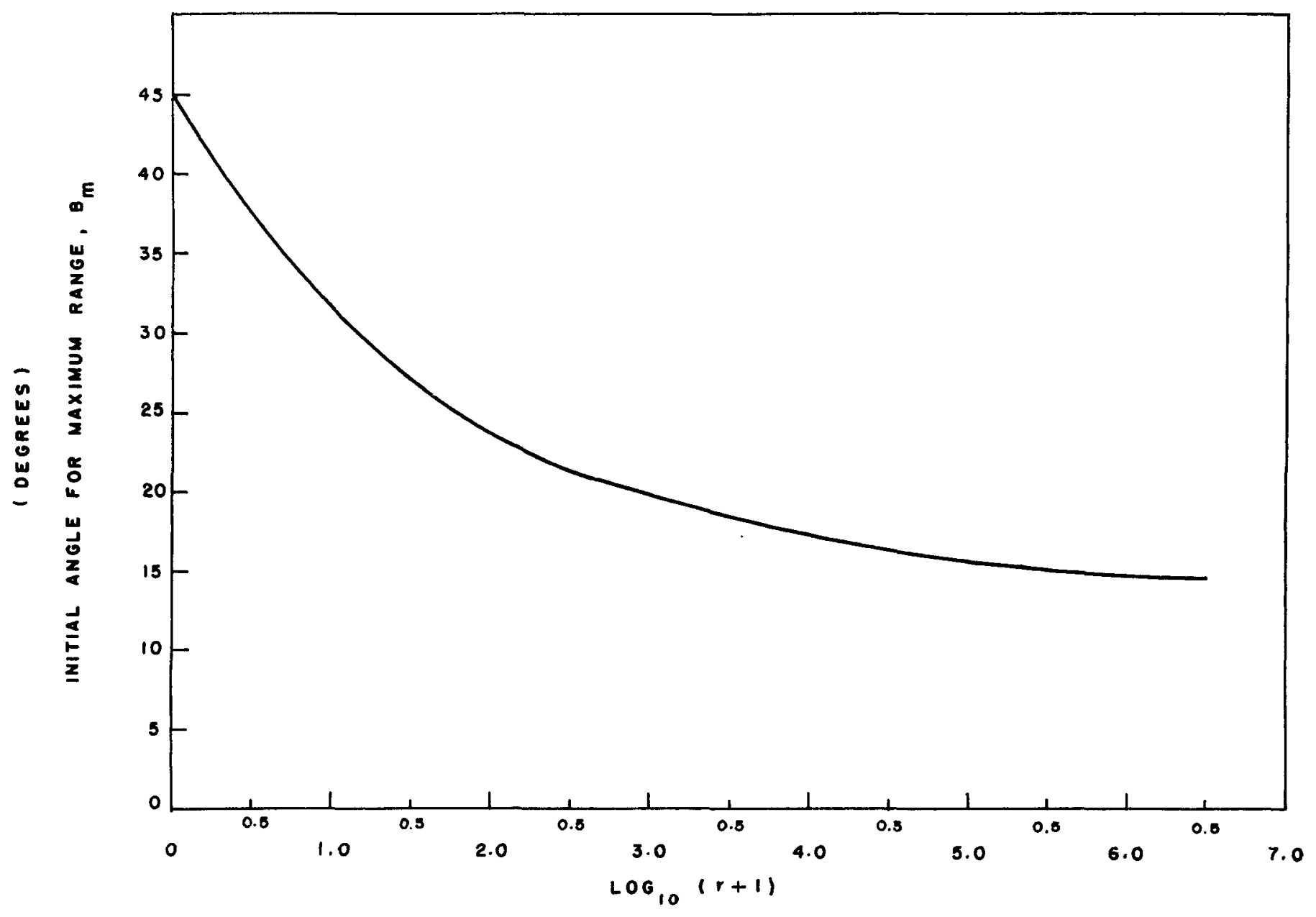

Fig. 3 - - Initial angle for maximum range 


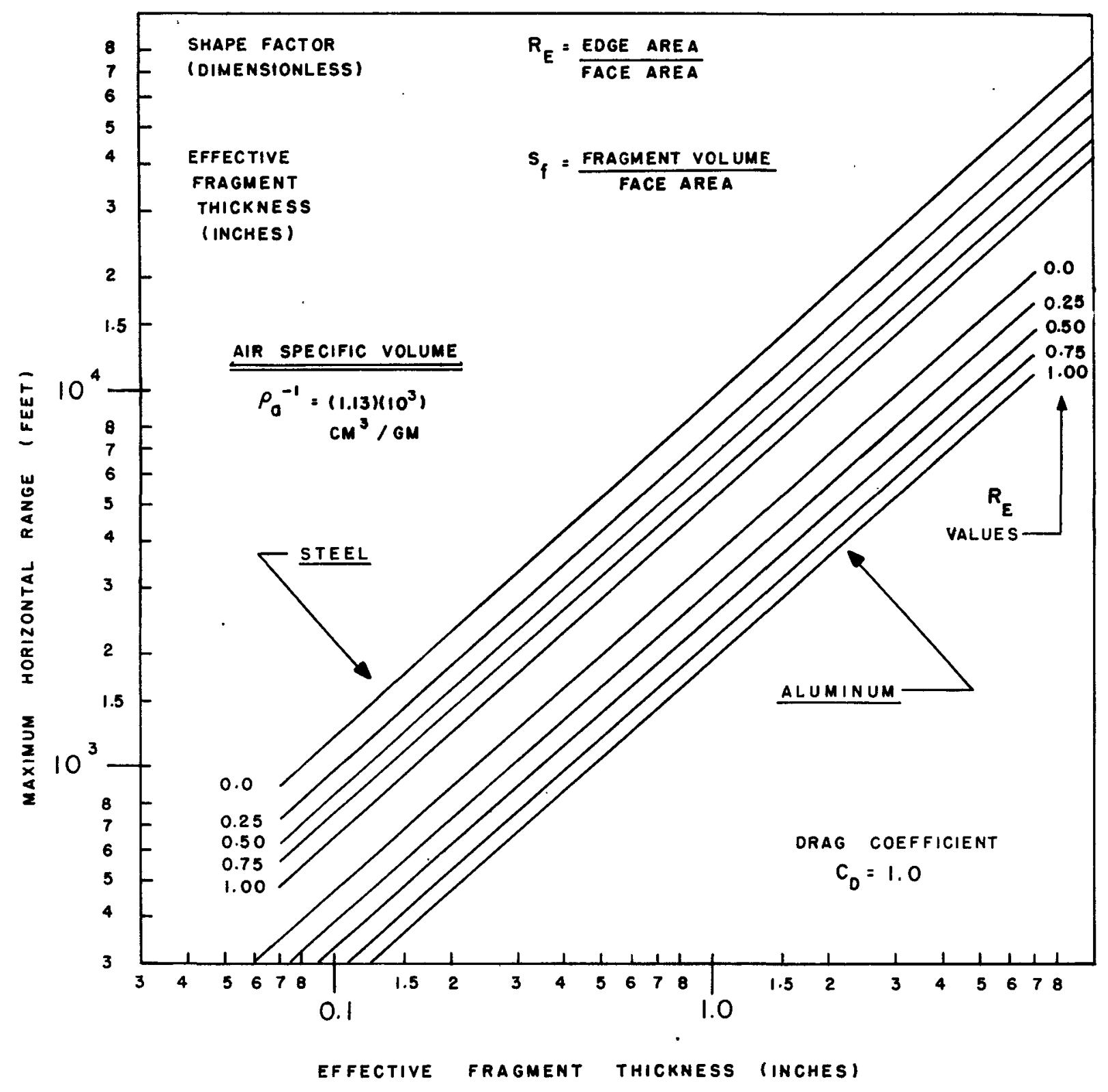

Fig. 4 - - Maximum ranges of fragments with initial speed of $10,000 \mathrm{ft} / \mathrm{sec}$ 


\section{APPENDIX}

\section{DERIVATION OF GENERAL TRAJECTORY FORMULAS}

\section{Differential Equations}

The motion of a projectile in air is retarded by a drag force $f_{D}$ which is proportional to the square of the projectile velocity $\mathrm{V}$ at any point along its path:

$$
\mathrm{f}_{\mathrm{D}}=(0.5) \mathrm{C}_{\mathrm{D}} \mathrm{A} \rho_{\mathrm{a}} \mathrm{V}^{2}
$$

by definition, with

$$
\begin{array}{cl}
f_{D} & \text { Drag force (dynes) } \\
C_{D} & \text { Drag coefficient (dimensionless) } \\
A & \text { Frontal projected area }\left(\mathrm{cm}^{2}\right) \\
\rho_{\mathrm{a}} & \text { Density of air }\left(\mathrm{gm} / \mathrm{cm}^{3}\right) \\
V & \text { Projectile velocity }(\mathrm{cm} / \mathrm{sec})
\end{array}
$$

The drag force $\mathrm{f}_{\mathrm{D}}$ results in a deceleration vector ${ }_{\mathrm{D}}$ for the projectile, directed 180 degrees relative to its velocity vector, as shown in Diagrams 1 and 2 below. The magnitude of the deceleration vector is determined by Newton's second law. Hence,

$$
a_{D}=m^{-1} f_{D}
$$

m Mass of projectile (grams)

${ }^{a}$ Deceleration of projectile due to $\operatorname{drag}\left(\mathrm{cm} / \mathrm{sec}^{2}\right)$

$\mathrm{f}_{\mathrm{D}} \quad$ Drag force (dynes) 
The direction of the velocity vector $\mathrm{V}$ is at an angle $\mathrm{b}$ with respect to the horizontal direction. The direction of the deceleration vector $a_{D}$ is at an angle
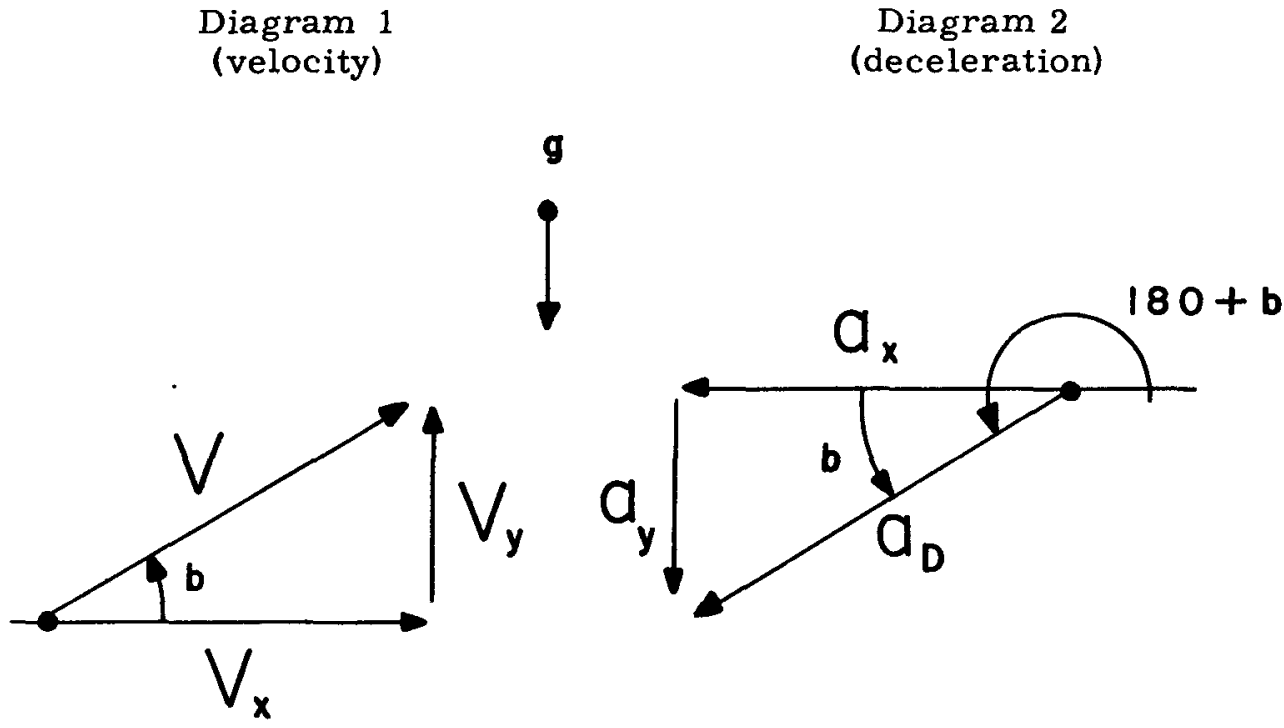

of $180^{\circ}+\mathrm{b}$ with respect to the (forward) horizontal direction, as indicated in Diagram 2.

Substituting the expression for $f_{D}$ from Eq A-1 into Eq A-2 gives

$$
a_{D}=k v^{2}
$$

with

$$
k=(0.5) \rho_{a} C_{D}(A / m)
$$

by definition,

where the symbols have already been defined following Eqs A-1 and A-2.

The physical meaning of the quantity $\mathrm{k}$ is made clear by expressing the drag deceleration $\mathrm{a}_{\mathrm{D}}$ in terms of the distance $\mathrm{S}$ along the path of the projectile. Let dS be the element of length along the path. The drag acceleration $\left(-a_{D}\right)$ is identically equal to

$$
-a_{D}=d V / d t=(d V / d S)(d S / d t)=V d V / d S
$$

Therefore, we may rewrite A-3 by substituting for ${ }^{a_{D}}$

$$
-\mathrm{V}(\mathrm{dV} / \mathrm{dS})=k \mathrm{~V}^{2}
$$


After dividing by $\mathrm{V}^{2}$ this becomes

$$
\frac{-d V / V}{d S}=k
$$

Equation $A-3^{\prime}$ shows that $k$ is simply equal to the relative fractional loss of velocity per unit distance along the trajectory, due to the influence of air resistance.

The deceleration $\mathrm{a}_{\mathrm{D}}$ of the projectile always acts in a direction opposite to its velocity, as shown in Diagrams 1 and 2, whereas the acceleration g due to gravity always acts in the same downward direction at every point along the projectile path. The angle $\mathrm{b}$ in Diagrams 1 and 2 is in general different for each point along the projectile path, since the direction of the velocity vector is continually changing. Thus it is necessary to resolve the drag deceleration $a_{D}$ into horizontal and vertical components, namely, $a_{x}$ and $a_{y}$ as indicated in Diagram 2. In terms of the angle $b$ these components may be expressed as

$$
\begin{aligned}
& a_{x}=a_{D} \cos b=k v^{2} \cos b \\
& a_{y}=a_{D} \sin b=k v^{2} \sin b
\end{aligned}
$$

in which $\mathrm{a}_{\mathrm{D}}$ has the magnitude given by Eq A-3. The total resultant projectile acceleration components due to the combined effect of gravity and drag are therefore

$$
\begin{gathered}
d V_{x} / d t=-k V^{2} \cos b \\
d V_{y} / d t=-g-k V^{2} \sin b
\end{gathered}
$$

in which the horizontal and vertical components $\mathrm{V}_{\mathrm{x}}$ and $\mathrm{V}_{\mathrm{y}}$ of the velocity vector $\mathrm{V}$ are as indicated by Diagram 1. In terms of the rectangular coordinates of the projectile, $x$ and $y$, and the time $t$

$$
\begin{aligned}
& V_{x}=d x / d t \\
& V_{y}=d y / d t
\end{aligned}
$$

by definition.

In Eqs A-7 and A-8 the projectile acceleration components $d V_{x} / d t$ and $d_{y} / d t$ are both negative, because the projectile velocity is decreasing as the time $t$ is increasing. 
From Eqs A-9 and A-10 and the definition of the tangent of $b$ in Diagram 1

$$
v_{y} / v_{x}=\tan b=d y / d x
$$

From Diagram 1 and the definitions of the sine and cosine

$$
\begin{aligned}
& \cos b=v_{x} / V \\
& \sin b=v_{y} / V
\end{aligned}
$$

Dividing Eq A-8 by Eq A-7 gives

$$
d V_{y} / d V_{x}=\tan b+g\left(k V^{2}\right)^{-1}(\sec b)
$$

Introducing a new variable, let

$$
u=\tan b
$$

by definition.

Then from Eq A-11

$$
\mathrm{v}_{\mathrm{y}}=\mathrm{u} \mathrm{v}_{\mathbf{x}}
$$

Differentiating Eq A-16 with respect to $\mathrm{V}_{\mathbf{x}}$ results in

$$
d V_{y} / d V_{x}=u+V_{x}\left(d u / d V_{x}\right)
$$

Substituting the value of $\mathrm{dV}_{\mathrm{y}} / \mathrm{dV}_{\mathrm{x}}$ from Eq A-17 into Eq A-14 and noting that $u=\tan \mathrm{b}$ as defined in Eq A-15 we obtain

$$
V_{x}\left(d u / d V_{x}\right)=g\left(k V^{2}\right)^{-1}(\sec b)
$$

From Eq A-12

$$
V=V_{x}(\sec b)
$$

Substituting the value of V from Eq A-19 into Eq A-18 and dividing by $V_{x}$ gives

$$
d u / d V_{x}=g V_{x}^{-3}\left[\left(k^{-1}\right)(\cos b)\right]
$$




$$
\begin{aligned}
& \text { If we define }\left\{\begin{array}{l}
Q=\text { average value of }(\cos b)=(\cos b)_{a} \\
w=\text { average value of } k^{-1}(\cos b)=\left(k^{-1}\right)_{a}(\cos b)_{a}
\end{array}\right. \\
& w=\left(k^{-1}\right)_{a} Q=\left(k^{-1}\right)_{a}(\cos b)_{a}
\end{aligned}
$$

in which $\mathrm{w}$ is the average value of $\mathrm{k}^{-1}(\cos \mathrm{b})$ along a short arc of the trajectory. Then one can integrate Eq A-20 along this short arc for which $\mathrm{k}^{-1}$ ( $\cos b$ ) is nearly constant. Integrating $A-20$, using $A-21$, gives

$$
u=u_{B}+(0.5) g w\left(v_{1}^{-2}-v_{x}^{-2}\right)
$$

where $u_{B}$ is the initial value $u$ and $v_{1}$ is the initial value of $v_{x}$ at the beginning of the short arc of the trajectory. From Eqs $A-21$ and $A-4$

$$
w=2\left(\rho_{a} C_{D}\right)_{a}^{-1}(m / A) Q
$$

in which average values of $C_{D}$ and $\rho_{a}$ along the short arc must be used, as well as $Q$ which is the average value of $(\cos b)$. Let the initial value of $b$ at the beginning of the short arc of the trajectory be defined as B. Then from Eqs A-15 and A-12

$$
\begin{gathered}
\mathrm{u}_{B}=\tan B \\
v_{1}=v_{B} \cos B
\end{gathered}
$$

in which $V_{B}$ is the initial value of $V$ at the beginning of the arc. In other words, $V_{B}$ is the initial magnitude of the velocity vector. Thus all the quantities have been defined, that appear in Eq A-22. From Eqs A-15 and A-11 it follows that in Eq A-22

$$
u=d y / d x=\text { slope of } t \text { rajectory }
$$

where $\mathrm{x}$ and $\mathrm{y}$ are the rectangular coordinates of the projectile at any point along its path, relative to the starting point. In order to carry out the integration of Eq A-22 to determine the shape of the projectile path in terms of the rectangular coordinates $\mathrm{x}$ and $\mathrm{y}$, it is necessary to evaluate the unknown horizontal velocity component $V_{x}$ which appears in Eq A-22. To determine $V_{x}$ it is evident that Eq A-7 must be integrated. To do this we note that

$$
d V_{x} / d t=\left(d V_{x} / d x\right)(d x / d t) \text {, identically. }
$$


But from Eq A-9 this can be written as

$$
d V_{x} / d t=V_{x}\left(d V_{x} / d x\right)
$$

Substituting the expression for $\mathrm{dV}_{\mathrm{x}} / \mathrm{dt}$ from Eq A-28 and the expression for $\mathrm{V}$ from A-19, the acceleration formula, Eq A-7, is modified so that only the unknown quantities $x$ and $V_{x}$ are present.

$$
\mathrm{dV}_{\mathrm{x}} / \mathrm{dx}=-\mathrm{k}(\sec \mathrm{b}) \mathrm{V}_{\mathrm{x}}
$$

In obtaining Eq A-29, we have divided both sides of the intermediate equation by $\mathrm{V}_{\mathrm{x}}$ (which may be done legitimately, since $V_{x}$ is never equal to zero). Equation A-29 may be rearranged to give

$$
\frac{d V_{x}}{V_{x}}=-\frac{d x}{k^{-1}(\cos b)}
$$

Over a short section of trajectory for which $k^{-1}(\cos b)$ is nearly constant, we use the average value defined by Eq A-21, and Eq A-30 becomes

$$
d v_{x} / v_{x}=-d x / w
$$

in which the explicit representation of $\mathbf{w}$ is given by Eq A-23. Integrating Eq A-31 we obtain

$$
\log _{e}\left(v_{x} / v_{1}\right)=-x / w
$$

in which $V_{x}=V_{1}$ when $x=0$ at the beginning point of the trajectory, as defined by Eq A-25. Solving for $\mathrm{V}_{\mathrm{x}}$ gives

$$
v_{x} / v_{1}=\exp (-x / w)
$$

in which exp is the exponential function to the base e.

In Eq A-32 all the symbols have been defined previously. In particular, the expression for $w$ is given by Eq A-23. From Eq A-32 it is evident that $w$ is the horizontal distance $x$ at which the horizontal velocity component $V_{x}$ has fallen to $1 / e$ of its initial magnitude. Note that $\exp (-1)=1 / e=1 / 2.72=0.368$, because of the properties of the exponential function. Thus $w$ may be called the "relaxation distance".

The time of flight $t_{x}$ is found from substituting the expression for $V_{x}$ from A-9 into A-32 and taking the reciprocal. This gives

$$
d x / d t=v_{1} \exp (-x / w)
$$




$$
d t / d x=v_{1}^{-1} \exp (x / w)
$$

Integrating Eq A-34 between limits $t=0$ vrhen $x=0$ to $t=t_{x}$ at a horizontal distance $x$ along the trajectory measured from the beginning the time of flight $t_{x}$ is

$$
t_{x}=\left(w / V_{1}\right)(-1+\exp x / w)
$$

in which $t_{x}$ is in seconds if $w$ is in feet and $v_{1}$ is in feet per second.

In order to find the vertical height y Eq A-22 must be integrated. Substituting the expression for $u$ from $E q A-26$, the expression for $V_{x}$ from Eq A-32, and the expression for $u_{B}$ from Eq A-24, Eq A-22 can be written as

$$
\frac{\mathrm{dy} / \mathrm{dx}}{\tan \bar{B}}=1-\mathrm{F}^{-1}[-1+\exp (2 \mathrm{x} / \mathrm{w})]
$$

in which, by definition,

$$
F=2(w g)^{-1} V_{1}^{2}(\tan B)
$$

and $V_{1}$ is given by Eq A-25.

Substituting the expression for $V_{1}$ from Eq A-25 into Eq A-37, and observing that

$$
2 \sin B \cos B=\sin 2 B
$$

from trigonometry, Eq A - 37 becomes

$$
F=(w g)^{-1} V_{B}^{2} \sin 2 B
$$

in which $V_{B}$ is the initial magnitude of the projectile velocity, at the beginning of its path.

Integrating Eq A-36 with the initial condition $y=0$ when $x=0$ at the beginning of the trajectory, we find

$$
y / x=(\tan B)\left(1-F^{-1} E_{x}\right)
$$

in which, by definition,

$$
E_{x}=-1+(2 x / w)^{-1}[-1+\exp (2 x / w)]
$$

The horizontal distance of any point along the trajectory is $x$, measured from the starting point. The "relaxation distance" is $\mathrm{w}$ which is given by Eq A-23. The dimensionless distance ratios $\mathrm{x} / \mathrm{w}$ and $2 \mathrm{x} / \mathrm{w}$ appear in Eqs $\mathrm{A}-40, \mathrm{~A}-36, \mathrm{~A}-35$, and $\mathrm{A}-32$. For this reason it is convenient to define a new symbol $z$ to represent one of these dimensionless 
distance ratios. Let

$$
z=2 x / w
$$

by definition. Then the fundamental trajectory formulas, Eqs A-40, A-36, A-35, and A-32 can all be expressed in a simplified form in terms of this new dimensionless distance ratio, z.

Using $A-41$, the definition of $E_{x}$ in Eq A-40 becomes

$$
E_{x}=-1+z^{-1}(-1+\exp z)
$$

Substituting the expression for $\mathrm{E}_{\mathrm{x}}$ from $\mathrm{Eq} \mathrm{A}-42$ into $\mathrm{Eq} \mathrm{A}-39$, we find the equation of the trajectory in rectangular coordinates $\mathrm{x}$ and $\mathrm{y}$

$$
\frac{y / x}{\tan B}=1-F^{-1}\left[-1+z^{-1}(-1+\exp z)\right]
$$

in which $\mathrm{z}$ is defined by Eq A-41 in terms of the horizontal distance $\mathrm{x}$ and the relaxation distance $w$. The relaxation distance $w$ is given by Eq A-23. Using Eq A-41, the slope formula Eq A-36 can be written as

$$
\frac{\tan b}{\tan B}=\frac{V / V}{\tan B}=1-F^{-1}(-1+\exp z)
$$

in which we have used the various equivalent slope representations

$$
\tan b=d y / d x=v_{y} / V_{x}
$$

from $\mathrm{Eq} \mathrm{A-11.} \mathrm{(Note} \mathrm{that} \mathrm{b}$ is the angle of the velocity vector.)

In order to illustrate the use of these formulas, let us find the altitude of the highest point of the trajectory. This is found from the equation of the trajectory, $A-43$, which gives the altitude $\mathrm{y}$ in terms of the horizontal distance $\mathrm{x}$. The horizontal distance $\mathrm{x}$ corresponding to the highest point of the trajectory is found from Eq A-44 which gives the slope of the trajectory, $\tan b$, at any point. At the highest point of the trajectory the projectile is moving horizontally, and the velocity vector angle $b$ is zero (relative to the horizontal direction). Thus $\tan b=0$ and $E q A-44$ then requires that

$$
\mathrm{F}=-1+\exp \mathbf{z}_{\mathrm{m}}
$$


in which $z_{m}$ represents the particular value of $z$ corresponding to the distance $x$ at which the highest point of the trajectory occurs. Thus from Eq A-41, solving for $\mathrm{x}$ gives the horizontal distance $\mathrm{x}_{\mathrm{m}}$ at which the highest point is located:

$$
\mathrm{x}_{\mathrm{m}}=(0.5) \mathrm{wz} \mathrm{m}
$$

The value of $\mathrm{z}_{\mathrm{m}}$ must be determined from Eq A-45 by solving for $\mathrm{z}_{\mathrm{m}}$, which gives

$$
z_{m}=\log _{e}(1+F)
$$

in which $F$ is defined by Eq A-38. Having determined $x_{m}$ and $z_{m}$, we substitute these values into $\mathrm{Eq} \mathrm{A-43}$ to determine the maximum trajectory altitude $\mathrm{y}_{\mathrm{m}}$

$$
\mathrm{y}_{\mathrm{m}}=\mathrm{x}_{\mathrm{m}}(\tan \mathrm{B})\left\{1-\mathrm{F}^{-1}\left[-1+\mathrm{z}_{\mathrm{m}}^{-1}\left(-1+\exp \mathrm{z}_{\mathrm{m}}\right)\right]\right\}
$$

\section{Horizontal Range}

It is frequently required to determine the horizontal range $x_{R}$ for a trajectory, as well as the maximum altitude $y_{m}$. The range $x_{R}$ is defined as the distance $x$ in Eq A-43 at which the relative vertical altitude $y$ is equal to zero. Since $x$ is never zero except at the beginning of the trajectory, this condition applied to Eq A-43 requires that the square bracket must be equal to $F$. Thus,

$$
F=-1+z_{R}^{-1}\left(-1+\exp z_{R}\right)
$$

in which $z_{R}$ represents the particular value of $z$ corresponding to the range distance $x_{R}$ in Eq A-41. Thus in this case we solve Eq A-41 for $x$ and substitute $x_{R}$

$$
\mathrm{x}_{\mathrm{R}}=(0.5) \mathrm{wz}_{\mathrm{R}}
$$

Note that $z_{R}$ is the solution of Eq A-49 above, and $x_{R}$ is the horizontal range.

It is impossible to solve Eq A-49 explicitly for $z_{R}$ in terms of $F$ using elementary functions, unless an infinite series is used. For specific numerical solutions, one must use trial and error, Newton's method of approximation, or some graphical method. A graphical method is illustrated in Fig. 2 in which $F$ is plotted in terms of $z_{R}$ when $z_{R}$ does not exceed 3. 0. When $z_{R}$ is greater than 2 the rapid change of exp $z_{R}$ makes it desirable to use logarithms. Taking the logarithm of each side of Eq A-49, after adding 1 to each side of the equation, gives 


$$
\log _{10}(F+1)=\log _{10}\left[z_{R}^{-1}\left(-1+\exp z_{R}\right)\right]
$$

In Fig. 1 various values of $\log _{10}(F+1)$ have been plotted as a curve, in terms of the quantity $z_{R}$ according to Eq A-51. Note that $\log _{10}(F+1)=0$ when $z_{R}=0$. From Fig. 1 it is possible to determine $z_{R}$ from any given $F$ over a wide range. When $z_{R}$ is less than 2 it is preferable to use Fig. 2 instead of Fig. 1 because of the greater percentage accuracy with which $z_{R}$ can be read on the scale of the graph. The range of $F$ covered in Fig. 1 is expected to cover all cases occurring in practice, because the largest $F$ in Fig. 1 corresponds to an initial air resistance $r$ of about one million times gravity. (See Eq A-103 in which $\mathrm{N}_{\mathrm{r}}$ is small compared to 1. 0.)

For values of $z_{R}$ greater than 4. 0, the right side of Eq A-49 can be represented to a very close approximation by the more simple function

$$
\mathrm{z}_{\mathrm{R}}^{-1} \exp \mathrm{z}_{\mathrm{R}}
$$

Therefore,

$$
F \cong z_{R}^{-1} \exp z_{R}
$$

when $z_{R}$ is greater than 4.0 .

If the relaxation distance $\mathrm{w}$ given by Eq A-23 is nearly constant along a section of a trajectory, the conditions at the end of the section can be calculated with adequate accuracy from the conditions at the beginning of the section.

This follows because the value of $\mathrm{k}^{-1}(\cos \mathrm{b})$ at any point along the section is never very far from the average value of $k^{-1}$ ( $\cos b$ ) defined as $w$ in Eqs A-21 and A-23. In general, the total trajectory must be divided into sections over which the drag coefficient $C_{D}$ is nearly constant, because the drag coefficient variation is usually the major cause of change in $\mathrm{k}^{-1}$ ( $\cos \mathrm{b}$ ). For high-angle trajectories the variation of (cos b) must also be taken into account, since $b$ varies over a wider range for different points along the trajectory. The air density $\rho_{\mathrm{a}}$ also varies along a trajectory section, and this variation must be included in the accurate calculation of any projectile path which rises vertically more than about 3300 feet above the starting point. An altitude change of 3300 feet (1.0 kilometer) results in an air density change of about 10 percent, according to the NACA standard atmosphere, quoted in Ref 3, page 3130 .

If an average air density is used in the calculation, the air density at any point would always be within \pm 5 percent of the average density for any trajectory which rises less than 3300 feet above the starting point. 
Assuming sufficiently constant conditions over the entire trajectory, one can determine approximately the initial angle $B_{m}$ at which the maximum range $\left(x_{R}\right)_{\max }$ occurs in Eq A-50. In a vacuum the maximum range occurs when the initial angle $B$ is 45 degrees. Thus,

$$
\left(B_{m}\right)_{\text {vac }}=45 \text { degrees }
$$

The air resistance changes this, and $\left(\mathrm{B}_{\mathrm{m}}\right)$ is no longer 45 degrees. To calculate the magnitude of the initial angle $\left(\mathrm{B}_{\mathrm{m}}\right)$ which results in the maximum horizontal range, the procedure is to differentiate the range $x_{R}$ with respect to $B$ and set the result equal to zero. Thus,

$$
\left(\mathrm{dx}_{\mathrm{R}} / \mathrm{dB}\right)=0
$$

when

$$
\mathrm{B}=\mathrm{B}_{\mathrm{m}}
$$

Substituting the expression for $x_{R}$ from Eq A-50 into Eq A-53

$$
z_{R}^{-1}\left(d z_{R} / d B\right)=-w^{-1}(d w / d B)
$$

when

$$
\mathrm{B}=\mathrm{B}_{\mathrm{m}}
$$

Note that $w$ is obtained from Eq A-21 and Eq A-4. Thus,

$$
\mathrm{w}=\mathrm{Qk}_{\mathrm{a}}^{-1}
$$

Also,

$$
k_{a}^{-1}=2\left(\rho_{a} C_{D}\right)_{a}^{-1}(m / A)
$$

from $\mathrm{Eq} \mathrm{A-4}$, and

$$
Q=(\cos b)_{a}
$$

by definition from Eq A-21.

Differentiating Eq A-52 with respect to B gives

$$
F^{-1}(d F / d B)=\left(z_{R}-1\right) z_{R}^{-1}\left(d z_{R} / d B\right)
$$


in which $z_{R}$ must always be greater than 4.0 .

Differentiating Eq A-38 with respect to B gives:

$$
d F / d B=(w g)^{-1} V_{B}^{2}\left[2(\cos 2 B)-w^{-1}(\sin 2 B)(d w / d B)\right]
$$

Differentiating Eq A-55 with respect to B gives

$$
\mathrm{dw} / \mathrm{dB}=\mathrm{k}_{\mathrm{a}}^{-1}(\mathrm{dQ} / \mathrm{dB})
$$

From Eqs $A-60$ and $A-55$

$$
\mathrm{w}^{-1}(\mathrm{dw} / \mathrm{dB})=\mathrm{Q}^{-1}(\mathrm{dQ} / \mathrm{dB})
$$

Dividing Eq A-59 by Eq A-38 gives

$$
F^{-1}(d F / d B)=2(\operatorname{ctn} 2 B)-w^{-1}(d w / d B)
$$

Substituting the expression for $F^{-1}(d F / d B)$ from $E q A-62$ into Eq A-58 we obtain:

$$
\mathrm{z}_{\mathrm{R}}^{-1}\left(\mathrm{dz} \mathrm{z}_{\mathrm{R}} / \mathrm{dB}\right)=\frac{2 \operatorname{ctn} 2 \mathrm{~B}-\mathrm{w}^{-1}(\mathrm{dw} / \mathrm{dB})}{\mathrm{z}_{\mathrm{R}}-1}
$$

Substituting the expression for $z_{R}^{-1}(d z / d B)$ from Eq A-63 into Eq A-54 and solving for $z_{R}$.

$$
\mathrm{z}_{R}=2-2\left[\mathrm{w}^{-1}(\mathrm{dw} / \mathrm{dB}) \tan 2 \mathrm{~B}\right]^{-1}
$$

Substituting the expression for $w^{-1}(d w / d B)$ from Eq A-61 into Eq A-64 gives, for $z_{R}$ greater than 4.0 ,

$$
(0.5) z_{R}=1-\left[Q^{-1}(d Q / d B) \tan 2 B\right]^{-1}
$$

Since the relation between $Q$ and $B$ is unknown at present, it is not possible to proceed further with the solution of Eq A-65 until an analysis of $Q$ has been carried out. Then the initial angle $B_{m}$ for maximum range can be found from the fundamental equation, Eq A-65, for any given magnitude of $z_{R}$.

\section{Asymmetric Trajectories}

The derivation of Eq A-65 is based on the asymptotic formula, Eq A-52, which gives the approximate relation between $F$ and $z_{R}$ for all $z_{R}$ which are greater than 4.0 . It will be proved that the air resistance $r$, compared to the acceleration of gravity, is proportional 
to $F$. Also, $z_{R}$ depends on $\log _{10}(F+1)$ according to the curve in Fig. 1, which shows that a very large value for $F$ results from a small value for $z_{R}$. When $z_{R}$ is greater than 7. 0 the air resistance is, therefore, quite large compared to gravity.

Just how large this air resistance can become should be investigated, because it turns out that the shape of the trajectory approaches a limiting form when this resistance is large. From this limiting trajectory shape it is possible to estimate the dependence of $Q$ relative to the initial trajectory angle $B$. From this relation of $Q$ with respect to $B$ it is possible to determine $Q^{-1}(d Q / d B)$ which can be substituted into the fundamental formula, Eq A-65. Finally, the determination of the initial angle $B$ for maximum range can be determined from Eq $A-65$ after $Q^{-1}(d Q / d B)$ has been obtained.

Let the dimensionless ratio of the "initial" air resistance deceleration $a_{D}^{\prime}$ to the acceleration $g$ due to gravity be defined as $r$. Then,

$$
r=a_{D}^{\prime} / g
$$

From Eq A-3, using the initial velocity $V_{B}$ and the average value of $k$ along the trajectory (which is defined as $\mathrm{k}_{\mathrm{a}}$ ),

$$
a_{D}^{\prime}=k_{a} v_{B}^{2}=\text { "initial" deceleration* }
$$

From Eq A-67, substituting $a_{D}^{\prime}$ into Eq A-66

$$
\mathrm{r}=\mathrm{g}^{-1} \mathrm{k}_{\mathrm{a}} \mathrm{v}_{\mathrm{B}}^{2}
$$

The relaxation distance $w$ also depends on $k_{a}$ according to Eq A-55

$$
\mathrm{w}=\mathrm{k}_{\mathrm{a}}^{-1} \mathrm{Q}
$$

which may be solved for $\mathrm{k}_{\mathrm{a}}$

$$
\mathrm{k}_{\mathrm{a}}=\mathrm{w}^{-1} \mathrm{Q}
$$

Substituting $\mathrm{k}_{\mathrm{a}}$ from $\mathrm{Eq} \mathrm{A-69}$ into $\mathrm{Eq} \mathrm{A-68}$

$$
r=(w g)^{-1} V_{B}^{2} Q
$$

\footnotetext{
*As shown by Eq A-67, the "initial" deceleration a $\mathrm{D}$ is not really the exact initial deceleration, because $\mathrm{k}_{\mathrm{a}}$ is not exactly equal to $\mathrm{k}$. Use of $\mathrm{ka}$ in place of $\mathrm{k}$ is $\overline{\mathrm{r}}$ equired for mathematical convenience in order to make a simple derivation of Eq A-71, a relation of fundamental significance.
} 
Dividing Eq A-70 by Eq A-38 gives:

$$
r=F Q(\sin 2 B)^{-1}
$$

Equation A-71 shows that $\mathrm{r}$ is proportional to $\mathrm{F}$ as was stated previously. The factor of proportionality is $Q(\sin 2 B)^{-1}$. This depends on the unknown quantity $Q$ which is the average value of ( $\cos \mathrm{b}$ ) along the trajectory. Evidently this quantity $Q$ can not be closely estimated unless something is known in detail about the trajectory. All that can be stated with certainty in general is that

$$
0<\mathbf{Q}<1.0
$$

because ( $\cos b)$ is always in a range

$$
0<\cos b<1.0
$$

The range given by Eq A-73 follows from the trigonometric formula $\cos b=\cos (-b)$, since

$$
-90^{\circ}<\mathrm{b}<90^{\circ}
$$

for any trajectory if the effect of windage is neglected.

In order to determine $Q$ to within closer limits than those given by Eq A-72 we shall calculate a typically asymmetric shrapnel trajectory which starts off at an angle $B$ equal to 20 degrees. It will be proved later that this angle is somewhere near the angle which gives the maximum horizontal range. From Table II, already calculated, it can be seen that a typical aluminum fragment, less than 1.5 inches thick, has a value of $z_{R}$ equal to 10 or more. A value of

$$
\mathrm{z}_{\mathrm{R}}=11.0
$$

will be assumed in the calculation of the "representative" trajectory with $B=20$ degrees. By referring to Eq A-49, it is found that the magnitude of $F$ corresponding to $z_{R}=11.0$ is

$$
F=5500
$$

In order to determine $r$ from Eq A-71 it is necessary to determine sin $2 B$ as well as F.

It has been assumed that $\mathrm{B}=\mathbf{2 0}$ degrees for the particular trajectory under consideration. Therefore,

$$
\sin 2 \mathrm{~B}=\sin 40^{\circ}=0.64
$$


It will be proved later that the average value of $(\cos b)$ is nearly equal to $\cos B$. Hence, as a first approximation, we set

$$
\mathrm{Q}_{20}=\cos 20^{\circ}=0.94
$$

By using the magnitudes of $F$ and $Q$ and sin $2 B$ just determined, the air resistance $r$ is found from Eq A-71 to be equal to 8000. This means that the projectile is initially subjected to a decelerating force which is 8000 times as large as the force due to gravity. It is expected, therefore, that the shape of the trajectory for this large air resistance might be considerably different from the perfectly symmetric trajectory in a vacuum, or the nearly symmetric shape when $r$ is only a few times the gravity acceleration.

The most important quantities required to establish the general shape of a trajectory are:

$\begin{array}{lc}\text { Range } & \mathrm{x}_{\mathrm{R}} \\ \text { Maximum height } & \mathrm{y}_{\mathrm{m}} \\ \begin{array}{l}\text { Horizontal location of the } \\ \text { maximum height }\end{array} & \mathrm{x}_{\mathrm{m}} \\ \text { Angle of impact } & \mathrm{b}_{\mathrm{R}}\end{array}$

The angle of impact gives the direction of the projectile velocity at the point of impact, at a horizontal distance $x_{R}$ from the starting point (see Diagram 3, below Eq A-89). To determine $\mathrm{x}_{\mathrm{m}}$ and $\mathrm{y}_{\mathrm{m}}$ we use the fundamental trajectory formulas of Eqs A-46, A-47, and A-48 already derived.

From Eq A-48

$$
y_{m}=x_{m}(\tan B)\left(1-F_{m} / F\right)
$$

in which, by definition,

$$
F_{m}=-1+z_{m}^{-1}\left(-1+\exp z_{m}\right)
$$

From Eqs $A-46$ and A-47, using $F=5500$ as already determined for $z_{R}=11.0$ we find

$$
\mathrm{z}_{\mathrm{m}}=2 \mathrm{x}_{\mathrm{m}} \mathrm{w}^{-1}=8.6=\log _{\mathrm{e}} 5501
$$

Substituting the magnitude of $z_{m}$ from Eq A-81 into Eq A-80 gives:

$$
\mathrm{F}_{\mathrm{m}}=602
$$


Dividing Eq A-79 by $0.5 \mathrm{w}$ and using Eq A-81 we find

$$
2 y_{m} / w=z_{m}(\tan B)\left(1-F_{m} / F\right)
$$

Substituting

$$
\begin{aligned}
z_{m} & =8.6 \\
F & =5500 \\
F_{m} & =602 \\
B & =20 \text { degrees }
\end{aligned}
$$

into Eq A-83 gives the magnitude of $2 y_{m} / w$

$$
2 \mathrm{y}_{\mathrm{m}} / \mathrm{w}=2.8
$$

Since

$$
z_{m}=2 x_{m} / w=8.6
$$

from $\mathrm{Eq} A-81$, and

$$
z_{R}=2 x_{R} / w=11.0
$$

from Eqs A-50 and A-75, we obtain

$$
\begin{aligned}
& \mathrm{x}_{\mathrm{m}} / \mathrm{x}_{\mathrm{R}}=8.6 / 11=0.78 \\
& \mathrm{y}_{\mathrm{m}} / \mathrm{x}_{\mathrm{R}}=2.8 / 11=0.26
\end{aligned}
$$

It is also of interest to calculate the "impact angle" $b_{R}$ at which the projectile lands at the end of its path through the air. This is found from $(\tan b)$ for the value $z_{R}=11.0$ as assumed previously. From Eq A-44

$$
\frac{\tan b_{R}}{\tan \bar{B}}=1-F^{-1}\left(-1+\exp z_{R}\right)
$$

in which

$$
\begin{aligned}
\mathbf{z}_{R} & =11.0 \\
\tan B & =\tan 20^{\circ}=0.364 \\
F & =5500
\end{aligned}
$$

Substituting the above magnitudes into Eq A-87 we obtain

$$
\tan b_{R}=-4.0
$$


Evaluating Eq A-88,

$$
\begin{aligned}
& \tan \left(-b_{R}\right)=4.0 \\
& \operatorname{ctn}\left(-b_{R}\right)=0.25 \\
& \tan \left(90^{\circ}+b_{R}\right)=0.25 \\
& 90^{\circ}+b_{R}=14^{\circ} \\
& b_{R}=-90^{\circ}+14^{\circ} \\
& b_{R}=\text { Impact angle }
\end{aligned}
$$

The magnitudes given by Eqs A-89, A-85, and A-86 have been plotted to scale in Diagram 3. The scale is determined by the horizontal range $x_{R}$ which is taken to be $10 \mathrm{~cm}$.

\section{Diagram 3}

\section{Trajectory for Air Resistance}

$r=8000$ times Gravity

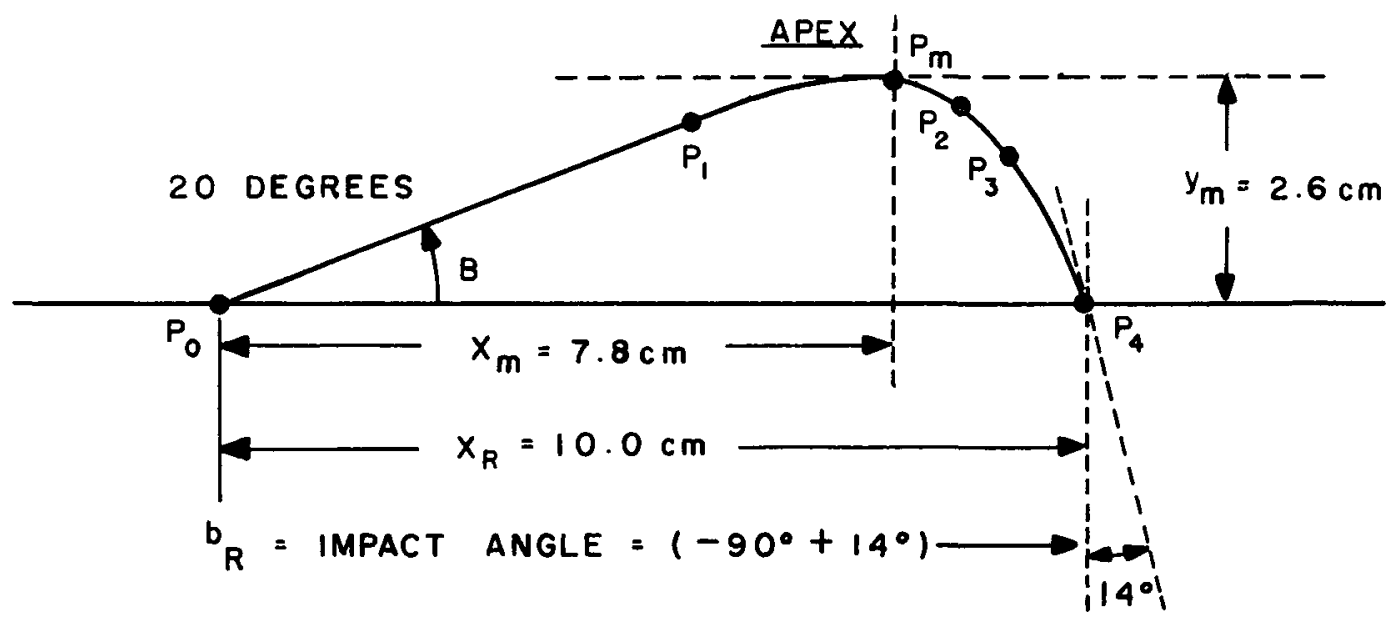

In the calculation of the trajectory form illustrated in Diagram 3 it has been assumed that the relaxation distance $\mathrm{w}$ has the same magnitude at all points along the trajectory. This follows from the definitions

$$
\begin{aligned}
& 2 x_{R} / w=z_{R} \\
& 2 x_{m} / w=z_{m} \\
& 2 y_{m} / w=\text { Relative altitude }
\end{aligned}
$$


from which Eqs A-85 and A-86 were derived. The use of a constant magnitude for w implies a constant value of $Q$ as shown by Eq A-21. Since a constant magnitude for $Q$ has therefore been assumed in calculating the trajectory shape in Diagram 3, it is necessary to investigate how closely the constant value,

$$
\mathrm{Q}_{20}=\cos 20^{\circ}=0.94 \text {, }
$$

from Eq A-78, actually applies to the trajectory. We are also assuming that a negligible change in $w$ occurs due to variation of $C_{D}$ or $\rho_{a}$ along the trajectory. Compare Eqs A-21 and A-23.

Considering the trajectory in Diagram 3, we see that $Q$ is practically equal to cos $B$

$$
Q=\cos B=\cos 20^{\circ}=0.94
$$

along the section from the points $P_{0}$ to $P_{1}$, since the section is almost a straight line between these points. Between the points $P_{1}$ and $P_{2}$ the trajectory angle $b$ changes from 20 degrees to zero (at the point $\mathrm{P}_{\mathrm{m}}$ ) and down to -20 degrees. Thus (cos b) changes from 0.94 to 1.0 and back to 0.94 , which gives (cos b) average $=Q_{P_{1}} P_{2}=0.97$ for the section between $P_{1}$ and $P_{2}$. Between points $P_{2}$ and $P_{3}$ (ie, along the section $P_{2} P_{3}$ ) the angle $b$ is approximately -45 degrees and $Q$ is 0.7 .

Thus the average value of $Q$ for the entire section $P_{1} P_{2} P_{3}$ is approximately

$$
\begin{aligned}
Q_{P_{1} P_{2} P_{3}} & =(0.5)(0.7+0.97) \\
& =0.84
\end{aligned}
$$

Finally, the average for the section $\mathrm{P}_{0} \mathrm{P}_{3}$ is nearly

$$
Q_{P_{0} P_{3}}=0.5(0.84+0.94)=0.89
$$

which only differs by 5 percent from the value $\cos B=0.94$ for the section $P_{0} P_{1}$. These results suggest that for a trajectory shape similar to Diagram 3, but with a different initial angle $B$, one can use an "effective" value of $Q$ in the calculation, in which $Q$ is defined by the following fundamental formula:

$$
Q=\left(1+N_{r}\right)(\cos B)
$$

where $\mathrm{N}_{\mathbf{r}}$ is an unknown relative fractional correction term which is, presumably, only a few percent. The subscript $\underline{r}$ implies that $N_{r}$ may vary with $r$ which is the initial relative air resistance compared to the force of gravity. Since we base $Q$ on the particular "average" 
value of ( $\cos b)$ along the entire trajectory which gives the correct range (which is unknown in advance), it is evident that Eq A-90 merely relates one unknown $Q$ in terms of another unknown $\mathrm{N}_{\mathrm{r}}$. The advantage comes about because $\mathrm{N}_{\mathrm{r}}$ can be shown to be nearly constant for different values of $\cos B$ and also nearly constant for a wide range of the relative air resistance $r$. Since $N_{r}$ depends on the shape of the trajectory, we would expect $N_{r}$ to remain nearly constant if the trajectory shape should remain nearly constant. On general principles, one expects that the trajectory shape should depend on the initial angle $B$ and on the initial relative air resistance $r$ compared to gravity. From the calculations leading to Diagram 3 we know that $r$ may be at least as large as 8000 , but the corresponding value for $z_{R}$ is only 11.0. Thus it seems reasonable to investigate how the trajectory shape varies with different values of $z_{R}$ for a fixed initial angle $B$.

The question arises as to how the trajectory shape should be described mathematically. The location of the highest point of the trajectory seems to be a significant parameter to indicate the shape, .because it is a direct measure of the amount of asymmetry. For perfectly symmetric trajectories (with any initial angle B) which occur when there is negligible air resistance deceleration $(r=0)$ the relative location of the highest point of the trajectory is exactly half way between the starting point and the impact point. Then

$$
\left(x_{m} / x_{R}\right)_{s}=0.50
$$

for perfect symmetry, where in general the symmetry parameter is defined to be the dimensionless distance ratio

$$
\begin{aligned}
\mathrm{x}_{\mathrm{m}} / \mathrm{x}_{\mathrm{R}}= & \text { Relative location of apex } \\
& \text { (See Diagram 3) }
\end{aligned}
$$

The departure from perfect symmetry would naturally be expressed as an "asymmetry" parameter given by

$$
\left(x_{m} / x_{R}-0.5\right)
$$

because the asymmetry parameter is zero for perfect symmetry, from Eq A-91.

From Eqs $A-46$ and $A-50$

$$
\begin{aligned}
\mathrm{x}_{\mathrm{m}} & =0.5 \mathrm{wz} \mathrm{m} \\
\mathrm{x}_{\mathrm{R}} & =0.5 \mathrm{wz} \mathrm{z}_{\mathrm{R}}
\end{aligned}
$$

so that Eq A-92 also can be expressed as

$$
\mathrm{z}_{\mathrm{m}} / \mathrm{z}_{\mathrm{R}}=\mathrm{x}_{\mathrm{m}} / \mathrm{x}_{\mathrm{R}}=\text { apex location }
$$


The evaluation of the ratio $z_{m} / z_{R}$ in Eq A-93 can be carried out in terms of the single variable $z_{R}$ by using Eq A-45. Solving Eq A-45 for $\exp z_{m}$ gives

$$
\exp z_{m}=1+F
$$

Substituting the expression for F from Eq A-49 into Eq A-94 we obtain

$$
\exp z_{m}=z_{R}^{-1}\left(-1+\exp z_{R}\right)
$$

which may be written also

$$
\exp z_{m}=z_{R}^{-1}\left(\exp z_{R}\right)\left[1-\exp \left(-z_{R}\right)\right]
$$

after factoring $\exp z_{R}$ from the parenthesis in Eq A-95. Solving Eq A-96 for $z_{m}$ by taking the logarithm of both sides of the equation,

$$
z_{m}=z_{R}-\log _{e} z_{R}+\log _{e}\left[1-\exp \left(-z_{R}\right)\right]
$$

Dividing both sides of Eq A-97 by $z_{R}$ we obtain the desired formula for $z_{m} / z_{R}$ in terms of $z_{R}$ for use in Eq A-93.

$$
z_{m} / z_{R}=1-z_{R}^{-1} \log _{e} z_{R}+z_{R}^{-1} \log _{e}\left[1-\exp \left(-z_{R}\right)\right]
$$

When $z_{R}$ is not less than 4 the third term on the right side of Eq A-98 is negligible compared to 1 as can be easily proved by expanding the logarithm of $\left[1-\exp \left(-z_{R}\right)\right]$. For example, when $\mathrm{z}_{\mathrm{R}}=4.0$,

$$
\exp (-4)=(55)^{-1}=0.018
$$

and $\log _{e}(1-0.018)$ is very nearly -0.018 from the expansion

$$
\log _{e}(1+n)=n-\frac{n^{2}}{2}+\ldots \ldots
$$

Therefore the absolute value of the third term on the right of Eq A-98 for $z_{R}=4.0$ is $(0.018)(1 / 4)=0.0045$, which is negligible compared to 1.0 being only 0.45 percent. When $z_{R}$ is greater than 4.0 the term is even less than 0.0045 . It is of interest to investigate the remaining expression for $z_{m} / z_{R}$ in Eq A-98 when $z_{R}$ becomes large. Then,

$$
z_{m} / z_{R}=1-z_{R}^{-1} \log _{e} z_{R}
$$

$\left[z_{R} \geq 4\right]$ 
Hence, finally, the relative horizontal location

$$
\mathrm{x}_{\mathrm{m}} / \mathrm{x}_{\mathrm{R}}
$$

of the highest point of the trajectory, or "apex", is found from Eqs A-99 and A-93 to be

$$
x_{m} / x_{R}=1-z_{R}^{-1} \log _{e} z_{R}
$$

when $z_{R}$ is not less than 4.0. Table A-I gives various $x_{m} / x_{R}$ calculated from Eq A-100 for integer $z_{R}$ from 4 to 12 .

Note: $\log _{e^{z}} z_{R}=2.3 \log _{10} z_{R}$

Corresponding magnitudes of F from Eq A-49 and $r$ from Eq A-71 are also given. The values of $r$ obtained from Eq A-71 are for

$$
\begin{aligned}
& Q=\cos 20^{\circ}=0.94=\cos \mathrm{B} \\
& B=20 \text { degrees }
\end{aligned}
$$

The representative trajectory shown in Diagram 3 was calculated for an initial angle $B$ equal to 20 degrees, and with $r=8000$.

TABLE A-I

Relative Apex Location for $B=20$ Degrees

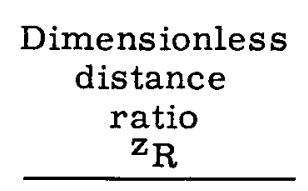

0

4

5

6

7

8

9

10

11 (Dia 3)

12

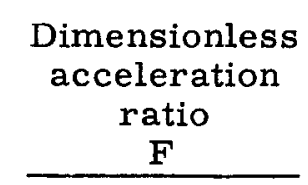

0

12.5

28. 7

66. 0

156.0

368.0

904.0

2240.0

5500.0

13400.0

\begin{tabular}{c} 
Relative \\
apex \\
location \\
$\mathrm{x}_{\mathrm{m}} / \mathrm{x}_{\mathrm{R}}$ \\
\hline
\end{tabular}

0.50

0.65

0.68

0.70

0.72

0.74

0.76

0.77

0.78

0.79

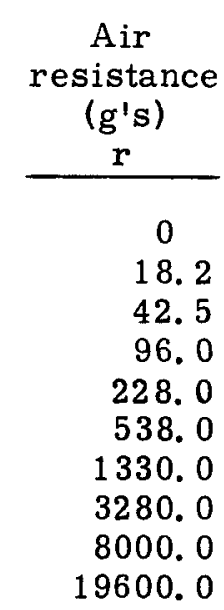

In Table A-I, above, the magnitudes corresponding to $z_{R}=11.0$

$$
\begin{aligned}
\mathrm{z}_{\mathrm{R}} & =11 \\
\mathrm{~F} & =5500 \\
\mathrm{r} & =8000 \\
\mathrm{x}_{\mathrm{m}} / \mathrm{x}_{\mathrm{R}} & =0.78
\end{aligned}
$$


have been determined already for the trajectory of Diagram 3. Also, in Table A-I the various magnitudes are all calculated for the single initial angle $B=20$ degrees.

The question now arises as to how the relative apex location $x_{m} / x_{R}$ changes when $B$ changes, for a given fixed value of the air resistance $r$.

From Eq A-71, and a simple trigonometric identity,

$$
r=F Q(2 \sin B \cos B)^{-1}
$$

From Eq A-90,

$$
Q=\left(1+N_{r}\right) \cos B
$$

Substituting the expression for $Q$ into Eq A-101 gives

$$
r=F(2 \sin B)^{-1}\left(1+N_{r}\right)
$$

Solving Eq A-102 for F

$$
F=2(\sin B)\left(1+N_{r}\right)^{-1} r
$$

The expression for $r$ in terms of primary physical quantities is easily determined from the fundamental definition in Eq A-68.

For a given fixed $r$, we see from $\mathrm{Eq} \mathrm{A-103}$ that $\mathrm{F}$ is nearly proportional to ( $\sin \mathrm{B}$ ), since $N_{r}$ is small and nearly constant. From Fig. 1 the quantity $z_{R}$ is nearly proportional to $\log _{10} \mathrm{~F}$, since the graph is nearly a straight line. Hence $\mathrm{z}_{\mathrm{R}}$ varies nearly as $\log _{10}$ ( $\sin B$ ), which means that $z_{R}$ varies slowly with respect to $B$. From Table A-I it is evident that the apex location changes slowly with respect to a change of $z_{R}$ when $z_{R}$ is greater than 5. 0 , or $r$ is greater than 40.0. Hence, finally, the apex location changes at a doubly slow rate with respect to a change of $B$.

From Eq A-103 we see that $F$ is not only proportional to ( $\sin B$ ) but also proportional to $r$. Therefore, the change of apex location in Table A-I due to a given fractional change of $r$ is exactly the same as the change of apex location due to the same fractional change of $(\sin B)$. This is proportional to the fractional change $(\mathrm{dB} / \mathrm{B})$, with a factor $(B \operatorname{ctn} B)$, since the fractional change of $(\sin B)$ is

$$
\frac{d(\sin B)}{\sin B}=\frac{(\cos B) d B}{\sin B}=[B(\operatorname{ctn} B)](d B / B) \cong(\cos B)(d B / B)
$$

Since the relative apex location $\mathrm{x}_{\mathrm{m}} / \mathrm{x}_{\mathrm{R}}$ changes at a very slow rate with respect to either $r$ or $B$, when $r$ is greater than 40 , the trajectory shape always remains fairly similar to the representative one shown in Diagram 3, for which it was shown that Eq A-90 
could be applied with good accuracy. Therefore, it should be possible to apply Eq A-90 over a wide range of $\mathrm{B}$ and $\mathrm{r}$.

Differentiating both sides of Eq A-90 with respect to B, we obtain

$$
\mathrm{dQ} / \mathrm{dB}=-\left(1+\mathrm{N}_{\mathrm{r}}\right) \sin \mathrm{B}
$$

Dividing Eq A-105 by Eq A-90

$$
Q^{-1}(d Q / d B)=-\tan B
$$

Substituting the expression for

$$
\mathrm{Q}^{-1}(\mathrm{dQ} / \mathrm{dB})
$$

from Eq A-106 into Eq A-65 gives the following fundamental formula for the initial angle $\mathrm{B}_{\mathrm{m}}$ at which the maximum horizontal range occurs:

$$
z_{R}=2\left(1+\operatorname{ctn} B_{m} \operatorname{ctn} 2 B_{m}\right)
$$

Equation A-107 applies only when $z_{R}$ is not less than 4. 0, as already explained. In order to relate the initial angle $B_{m}$ in $E q A-107$ to the relative air resistance $r$ for various magnitudes of $B_{m}$ and $r$, it is necessary to make intermediate calculations of $z_{R}$ and $F$. The steps in the procedure are:
(a) $z_{R}$ from $E q A-107$, given $B_{m}$
(b) $F$ from Eq A-49, using $z_{R}$
(c) $r$ from Eq A-102 using F from (b) and given $B_{m}$

In order to use Eq A-102 it is necessary to make some assumptions concerning $\mathrm{N}_{\mathrm{r}}$. If a constant value of $\mathrm{N}_{r}$ is not assumed, it is necessary to use a series of successive approximations to establish $\mathrm{N}_{\mathrm{r}}$ for each trajectory corresponding to a given value of $r$ and of $\mathrm{B}_{\mathrm{m}}$. This is not justified because of the already existing uncertainties in the variations of $\rho_{\mathrm{a}}$ and of $\mathrm{C}_{\mathrm{D}}$ along the trajectories. Hence it will be assumed, when $\mathrm{r}$ exceeds 40 , that $N_{r}=0$ since this is as good a constant value as is known over a wide range of $r$ and $B$. The required formulas are listed together for convenience of reference:
(a) $\mathrm{z}_{\mathrm{R}}=2\left(1+\operatorname{ctn} \mathrm{B}_{\mathrm{m}} \operatorname{ctn} 2 \mathrm{~B}_{\mathrm{m}}\right)$
(b) $F=-1+z_{R}^{-1}\left(-1+\exp z_{R}\right)$
(c) $r=F\left(2 \sin B_{m}\right)^{-1}$

The results of various calculations using (a), (b), and (c) are collected in Table A-II. The quantities $B_{m}$ and $\log _{10}(r+1)$ from Table $A-I I$ are plotted as a graph in Fig. 3. From Fig. 3, for any given air resistance $r$ over a wide range of typical magnitudes, one can 
immediately find the corresponding initial angle $B_{m}$ at which a projectile must be started in order to reach its maximum horizontal range, $\left(x_{R}\right)_{\max }$. The initial air resistance $r$ is obtained from Eq A-68 in terms of primary physical parameters of the projectile and the air.

TABLE A-II

Initial Angle for Maximum Range

\begin{tabular}{|c|c|c|c|c|}
\hline $\begin{array}{c}\text { Initial } \\
\text { angle } \\
\text { (degrees) } \\
\mathrm{B}_{\mathrm{m}} \\
\end{array}$ & $\begin{array}{c}\text { Distance } \\
\text { ratio } \\
\mathbf{z}_{\mathrm{R}} \\
\end{array}$ & $\begin{array}{c}\text { Acceleration } \\
\text { ratio } \\
\mathbf{F} \\
\end{array}$ & $\begin{array}{c}\text { Air } \\
\text { resistance } \\
\left(g^{\prime} s\right) \\
r\end{array}$ & $\begin{array}{l}\text { Quantity } \\
\text { plotted in } \\
\text { Fig. } 3 \\
\log _{10}(r+1)\end{array}$ \\
\hline 45 & 0 & 0 & 0 & 0 \\
\hline 30 & 4.0 & 12.5 & 12.5 & 1.13 \\
\hline 25 & 5.6 & 47.0 & 55.00 & 1.75 \\
\hline 22.5 & 6.8 & 133.0 & 173.0 & 2.24 \\
\hline 20 & 8.5 & 590.0 & 870.0 & 2.94 \\
\hline 17 & 11.7 & 1. $03\left(10^{4}\right)$ & 1. $77\left(10^{4}\right)$ & 4.25 \\
\hline 15 & 14.9 & 2. $0\left(10^{5}\right)$ & 3. $86\left(10^{5}\right)$ & 5.59 \\
\hline 10 & 33.2 & 6. $7\left(10^{12}\right)$ & $1.92\left(10^{13}\right)$ & $\ldots$ \\
\hline
\end{tabular}

For $B_{m}=45$ degrees, the air resistance $r$ is zero. From Eq A-102 it follows that $F=0$. Also, from the limit of Eq A-49, or from Fig. 2, we see that $z_{R}=0$. Finally, $\log _{10}(1+r)=0$ when $r=0$.

\section{Summary}

For convenience of reference, all the more fundamental trajectory formulas (equations) are collected and listed below with notes describing the location of the preceding formulas from which they were taken:

$$
\mathrm{k}^{-1}=\left(\rho_{\mathrm{a}}^{-1} / 15.25\right) \mathrm{C}_{\mathrm{D}}^{-1}(\mathrm{~m} / \mathrm{A})
$$

(converting Eq A-4 from $\mathrm{cm}$ to feet)

$\mathrm{k}^{-1} \quad$ A characteristic length (feet), related to the relaxation distance.

$\mathrm{k} \quad$ A deceleration parameter $\left(\right.$ feet $^{-1}$ ), which is defined as the fractional loss of velocity, per unit distance, due to air resistance (see A-3' above).

$\rho_{\mathrm{a}} \quad$ Air density $\left(\mathrm{gm} / \mathrm{cm}^{3}\right)=$ specific gravity relative to water.

$\mathrm{C}_{\mathrm{D}} \quad$ Drag coefficient (dimensionless).

$\mathrm{m} \quad$ Mass of projectile $(\mathrm{gm})$.

A Frontal projected area $\left(\mathrm{cm}^{2}\right)$. 
The use of Eq A-108 is simplified in many cases by expressing the projectile mass $\mathrm{m}$ in terms of its density and volume. Also, the volume can be expressed in cubic inches instead of $\mathrm{cm}^{3}$. Equation A-108 becomes

$$
\mathrm{k}^{-1}=(\mathrm{s} / 6)\left(\rho_{\mathrm{P}} / \rho_{\mathrm{a}}\right) \mathrm{C}_{\mathrm{D}}^{-1}
$$

$$
\begin{aligned}
& \mathrm{k}^{-1} \quad \text { Characteristic length (feet). } \\
& \text { s "Effective" }{ }_{3} \text { projectile thickness (inches), defined as the projectile } \\
& \text { volume (in }{ }^{3} \text { ), divided by the frontal projected area }\left(\mathrm{in}^{2}\right) \text {. } \\
& \rho_{\mathrm{P}} \quad \text { Projectile density }\left(\mathrm{gm} / \mathrm{cm}^{3}\right)=\text { specific gravity relative to water, } \\
& \text { defined as the mass }(\mathrm{gm}) \text {, divided by the volume }\left(\mathrm{cm}^{3}\right) \text {. } \\
& P_{a} \quad \text { Air density }\left(\mathrm{gm} / \mathrm{cm}^{3}\right) \text {. } \\
& C_{D} \quad \text { Drag coefficient (dimensionless). }
\end{aligned}
$$

From Eq A-21

$$
\mathrm{w}=\mathrm{k}_{\mathrm{a}}^{-1} \mathrm{Q}
$$

w Relaxation distance (feet).

$\mathrm{k}_{\mathrm{a}}^{-1} \quad$ Average value of $\mathrm{k}^{-1}$ along the trajectory.

$\mathrm{Q} \quad$ Average value of ( $\cos \mathrm{b})$ along the trajectory.

b Angle of velocity vector with respect to the horizontal direction.

From Eq A-90

$$
Q=(\cos B)\left(1+N_{r}\right)
$$

Q Average value of ( $\cos b$ ) along the trajectory.

$\mathrm{B} \quad$ Initial value of $\mathrm{b}$ at the beginning of the trajectory.

$\mathrm{N}_{\mathrm{r}} \quad$ Relative fractional correction term (small compared to 1.0 ).

From Eq A-68

$$
r=g^{-1} k_{a} v_{B}^{2}
$$

$r \quad$ Initial air resistance drag deceleration, divided by the acceleration due to gravity (dimensionless ratio).

g Acceleration due to gravity, $32 \mathrm{ft} / \mathrm{sec}^{2}$.

$\mathrm{V}_{\mathrm{B}} \quad$ Initial projectile velocity $(\mathrm{ft} / \mathrm{sec})$.

In other words, $r$ measures the initial drag on the projectile in terms of "g units". 
From Eq A-103

$$
\mathbf{F}=2 \mathrm{r}(\sin \mathrm{B})\left(1+\mathrm{N}_{\mathrm{r}}\right)^{-1}
$$

$F=$ Dimensionless deceleration ratio, related to the initial drag deceleration $r$.

Also, $F$ may be considered to be the vacuum range $\left(g^{-1} V_{B}^{2} \sin 2 B\right)$ divided

by the relaxation distance $w$, as expressed by Eq A-38.

The relaxation distance $\mathrm{w}$ is the horizontal distance at which the horizontal velocity component $\mathrm{V}_{\mathrm{X}}$ has declined to $1 / \mathrm{e}$ of its initial value $\mathrm{V}_{1}$ at the beginning of the trajectory. (See Eq A-32 below.)

From Eq A-41

$$
z=2(x / w)
$$

$\mathrm{x} \quad$ Horizontal distance along the trajectory (feet).

w Relaxation distance (feet).

z Dimensionless horizontal distance ratio.

From Eq A-32

$$
\mathrm{V}_{\mathrm{x}}=\mathrm{V}_{1} \exp (-\mathrm{x} / \mathrm{w})
$$

$\mathrm{V}_{\mathrm{x}} \quad$ Horizontal component of the projectile velocity at any point along the trajectory $(\mathrm{ft} / \mathrm{sec})$.

$\mathrm{V}_{1}$ Initial value of $\mathrm{V}_{\mathrm{x}}$ at the beginning of the trajectory $(\mathrm{ft} / \mathrm{sec})$.

From Eq A-35

$$
\mathrm{t}_{\mathrm{x}}=\left(\mathrm{w} / \mathrm{v}_{1}\right)[-1+\exp (\mathrm{x} / \mathrm{w})]
$$

$t_{x}=$ Time of flight (seconds) at horizontal distance $x$ (feet), along the trajectory.

From Eq A -44

$$
\frac{\tan b}{\tan B}=\frac{V_{y} / V_{x}}{\tan B}=1-F^{-1}(-1+\exp z)
$$

$\tan b=$ Slope of trajectory at any point

$\mathrm{V}_{\mathrm{y}}=$ Vertical component of the projectile velocity at any point along its trajectory (ft/sec)

From Eq A-43

$$
\frac{y / x}{\tan B}=1-F^{-1}\left[-1+z^{-1}(-1+\exp z)\right]
$$

$y=$ Vertical altitude (feet), relative to beginning point of the trajectory, at a horizontal distance $\mathrm{x}$ feet along the trajectory. 
From Eq A-79

$$
\mathrm{y}_{\mathrm{m}}=\mathrm{x}_{\mathrm{m}}(\tan \mathrm{B})\left(1-\mathrm{F}_{\mathrm{m}} / \mathrm{F}\right)
$$

From Eq A-80

$$
F_{m}=-1+z_{m}^{-1}\left(-1+\exp z_{m}\right)
$$

From Eqs A-47 and A-46

$$
z_{m}=\log _{e}(1+F)=2 x_{m} / w
$$

From Eq A-46

$$
x_{m}=(0.5) w z_{m}
$$

$\mathrm{y}_{\mathrm{m}}=$ Maximum vertical height (feet), of projectile, above the starting point.

$x_{m}=$ Horizontal distance (feet), of projectile when it is at its maximum vertical height.

From Eq A -50

$$
x_{R}=(0.5) w_{R}
$$

in which $z_{R}$ is the solution of the following equation.

From Eq A-49

$$
F=-1+z_{R}^{-1}\left(-1+\exp z_{R}\right)
$$

The solution $z_{R}$ of Eq A-49 is obtained from the graphs plotted in Figs. 1 and 2 .

From Eq A-107

$$
z_{R}=2\left(1+\operatorname{ctn} B_{m} \operatorname{ctn} 2 B_{m}\right)
$$

$\mathrm{B}_{\mathrm{m}}=$ Initial trajectory angle $\mathrm{B}$ at which a projectile will reach the maximum horizontal range $x_{R}$.

Values of $z_{R}$ have been calculated and collected in Table A-II for various $B_{m}$. Values of $B_{m}$ have been plotted as a graph in Fig. 3 in terms of the initial air resistance $r$. The initial air resistance $r$ is obtained from Eq A-68, above.

When $\mathrm{r}$ exceeds 40 , the correction term $\mathrm{N}_{\mathrm{r}}$ in $\mathrm{Eq} \mathrm{A-90}$ is taken to be zero except for very accurate trajectory calculations in which successive approximations are used, and the total trajectory is divided into sections over which $\mathrm{k}^{-1}$ and (cos b) are nearly constant. However, $N_{r}$ may be different from zero when the air resistance $r$ is less than 40 . 


\section{LIST OF REFERENCES}

1. Explosion Effects Data Sheets, U.S. Naval Ordnance Laboratory, White Oak, Maryland, NAVORD 2986, June 14, 1955, Confidential (Fig. C. 1, Gurney Law for Initial Fragment Velocity).

2. Hoerner, S. F., Fluid-Dynamic Drag, published by author, 1958.

3. Handbook of Chemistry and Physics, Chemical Rubber Publishing Co., Cleveland, 39th Edition, 1957-58, page 3130 .

4. Gurney, R. W., The Initial Velocities of Fragments from Bombs, Shells, and Grenades, BRL Report No. 405, Aberdeen Proving Ground, Maryland, September 14, 1943 . 


\section{INITIAL DISTRIBUTION}

M. T. Kincannon, Technical Advisor, FC, AFSWP, SWT

M. Olson, Rheem Mfg. Co., Downey, Calif.

H. W. Richardson, NOTS, Code 407, KAFB

J. L. McCraw, Office of Inspection and Storage Operations, ALO Dr. Ralph Ilsley, ASESB

Samuel Goldenberg, Lt. Col., AEC-DMA

J. O. Vineyard, UCRL

G. A. Fowler, Director of Research, 5100

A. B. Metzger, 3210

M. L. Merritt, 5110

J. R. Banister, 5150

J. E. Baylor, 3211

T. B. Cook, 5111

C. C. Hudson, 5111

M. Cowan, Jr., 5111

J. D. Shreve, Jr., 5112

E. F. Armbrust, 3211-1

L. J. Vortman, 5112-1

W. R. Perret, 5112-1

D. G. Palmer, 5112-2

Document Room (10)

B DISTRIBUTION:

R. H. Bishop, 5112 (12)

Documents, 3466-1 (13) 